\title{
¿LA GLOBALIZACIÓN DE LA INDIFERENCIA? ALGUNAS REFLEXIONES SOBRE LOS DESPLAZADOS, LOS MIGRANTES Y LOS REFUGIADOS EN LA UNIÓN EUROPEA
}

\section{THE GLOBALIZATION OF INDIFFERENCE? SOME REFLECTIONS ON DISPLACED PERSONS, MIGRANTS AND REFUGEES IN THE EUROPEAN UNION}

Núria Belloso Martín ${ }^{1}$

Recebido em: 10/10/2016 Aceito em: 26/12/2016

nubelo@ubu.es
Resumo: "Nuestro siglo XX es el siglo del miedo... la mayor parte de los hombres ... están privados de porvenir... (porque) vivir contra la pared es la vida de un perro".

Camus, A., Ni víctimas ni verdugos. El siglo del miedo, en Obras Completas, 290).

\section{INTRODUCCIÓN}

Existen alrededor de 60 millones de personas desplazadas forzosamente a nivel mundial. La inmigración es un fenómeno con larga tradición en Europa. El fenómeno de la migración es muy antiguo, porque la propia historia de la humanidad se ha fraguado a partir de movimientos migratorios. América del Norte y del Sur se poblaron principalmente con los inmigrantes que se desplazaron desde Europa. A su vez, Europa ha sido también receptora de personas que se desplazaron desde Asia y de África. Las corrientes migratorias han ido evolucionado al compás de los diversos acontecimientos políticos, económicos y sociales, derivados de catástrofes naturales, guerras civiles, conflictos armados, epidemias, hambre, crisis económica aguda.

Miles de personas refugiadas y migrantes están llegando a Europa, huyendo de las guerras y de la pobreza. En los últimos quince años, 30.000 personas han perdido la vida intentando cruzar el Mediterráneo. Se ha constituido un auténtico mercado alrededor de aquellos que disponen de medios para poder salir de su país. Han proliferado las mafias que se encargan de gestionar estos viajes (en pateras, en embarcaciones frágiles, escondidos como polizones en barcos). En 2015 llegaron a Europa casi un millón de personas refugiadas y migrantes. Para aprovechar las oportunidades y afrontar los retos generados por este tipo de movilidad internacional, la Unión Europea (UE) está intentando desarrollar un enfoque común en materia de inmigración y un sistema europeo común de asilo para proteger a los que buscan refugio en Europa por persecución o riesgo de daños graves en su país de origen.

\footnotetext{
${ }^{1}$ Universidad de Burgos - Burgos - Espanha
} 
La filosofía del Derecho tiene sentido porque no es una reflexión abstracta o fuera de contexto. La perspectiva de ofrecer un sentido crítico sobre la realidad social constituye uno de los ejes sobre los que se asienta la Filosofía jurídica. Así, reflexionar sobre el derecho de asilo puede tener que partir de un enfoque descriptivo. Pero este análisis necesita un momento posterior de reflexión iusfilosófica. La condición de los desplazados y los asilados es uno de los problemas que caracterizan la situación actual. Adorno escribió que después de Auswitch la filosofía no podía ser igual. En el actual momento de la historia, también cabría afirmar que la filosofía no puede ser igual en Europa después de los miles de desplazados (migrantes/refugiados) que tras arribar a las costas de un país europeo (Italia, Grecia) inician un peregrinaje por los diversos países de la Unión Europea.

Europa, casi desde sus inicios, ha sido un continente de recepción de inmigrantes y refugiados, no ha sido capaz de acordar una política común que regulara estas situaciones, muchas de las cuales constituyen una violación de los derechos humanos. Al proceso de en los últimos años, desde hace unos meses se ha sumado el de la llegada de refugiados demandantes de asilo procedentes principalmente de Siria pero también de países como Afganistán, Somalia o Eritrea que, huyendo de la guerra, intentaban reubicarse en algún país europeo. Son dos tipologías diferentes de sujetos de derechos, con una normativa diferenciada (requisitos de acceso y entrada a un país, tratamiento distinto) pero que, en la práctica, está resultando complejo diferenciar, lo que da lugar a resoluciones administrativas y judiciales -cuando no expulsiones masivas- injustas. En julio de 2015 ya había 40.000 personas en tránsito por Europa. La cifra total es de aproximadamente 120.000 asilados que solicitan ese asilo por el continente.

Los derechos humanos, entre ellos el asilo, son concretados, interpretados y realizados a través de diferentes instrumentos jurídicos nacionales e internacionales. La Unión Europea no tiene una política común de asilo, lo que ha desembocado en que cada país aplique su normativa. Sin embargo, la denominada "crisis de los refugiados" está poniendo a prueba la solidez de sus fundamentos. Hablar de asilo y refugio equivale a reivindicar la protección del género humano en la que encontramos una estricta vinculación entre los derechos humanos y la dignidad humana ${ }^{2}$, entendiendo ésta como "el portal a través del cual el contenido universal igualitario de la moral se importa el derecho"3.

En el presente trabajo vamos a analizar, en primer lugar, la definición conceptual de migrante, refugiado y asilado, a partir del Derecho Internacional de los Derechos humanos y del Derecho Internacional Público; seguidamente, nos ocuparemos de los instrumentos jurídicos de la política de asilo en la Unión Europea -Directivas, fases de tramitación- así como del derecho de asilo (orígenes, dificultades para concretar el asilo). A partir de estos instrumentos jurídico-políticos, analizaremos las dos medidas que, desde Bruselas, se han propuesto para intentar configurar una política común de asilo en la UE a partir de la avalancha de refugiados a las costas griegas e italianas entre los años 2015 y 2016. En este marco, analizaremos la primera medida que se adoptó, la política de

\footnotetext{
2 J. DE LUCAS, “Fundamentos filosóficos del derecho de asilo", Derechos y libertades: Revista del Instituto Bartolomé de las Casas, no 4, 1995, pp. 23-56; y, del mismo autor, Puertas que se cierran. Europa como fortaleza, Barcelona, Icaria, 1996.

3 HABERMAS, J., "La idea de dignidad humana y la utopía realista de los derechos humanos", Análes de la Cátedra Francisco Suárez, no 44, 2010, p. 111.
} 
distribución de refugiados en cada país de la UE mediante cuotas - propuesta que no ha funcionado-; la segunda medida adoptada ha sido el Acuerdo entre la Unión Europea (UE) y Turquía sobre la situación de los refugiados e inmigrantes que intentan llegar a Europa, adoptada en marzo de 2016. Este Acuerdo, que pretende solucionar la llamada "crisis de los refugiados", es extremadamente polémico y legalmente cuestionable: devolver a todos los que llegan a las islas griegas de nuevo a Turquía, independientemente de si son demandantes de asilo o los llamados emigrantes económicos, que no tienen derecho legal a quedarse por no huir de la guerra ni estar en peligro su vida en sus países. Concluiremos con unas reflexiones sobre la globalización de la indiferencia.

El acogimiento de refugiados mediante el derecho de asilo no es una cuestión fácil de dilucidar. No basta con diferenciar dos opciones, entre los partidarios de aceptar a todos, para no violar la dignidad humana ni quebrantar los Tratados de Derechos humanos y los partidarios de cerrar las fronteras y negar la entrada al extranjero, aplicando el derecho de devolución. La primera posibilidad, en la práctica, es inviable ya que no hay medios económicos ni estructuras organizativas (educación, sanidad) que puedan dar respuesta a estas demandas masivas. Pero tampoco se puede adoptar una respuesta exclusivamente negativa porque, además de que los demandantes de asilo tienen unos derechos humanos reconocidos por diversos textos y Tratados, la Unión Europea tiene como uno de sus fundamentos el reconocimiento y la garantía de los derechos humanos, lo que equivaldría a renegar de sus propios principios. Cómo llegar a una medida intermedia entre las dos posibilidades de aceptación amplia o de rechazo generalizado es lo difícil. En este trabajo pretendemos ofrecer algunas pautas para reflexionar sobre estas dos posibilidades.

\section{PRECISIONES CONCEPTUALES SOBRE MIGRANTES, REFUGIADOS Y SOLICITANTES DE ASILO}

El problema de los refugiados está muy vinculado a las mutaciones que se producen en la esfera internacional. Concretamente, en el siglo $X X$, en los años veinte fueron los rusos como consecuencia de la revolución soviética, en los años treinta y cuarenta, los perseguidos por los nazis y fascistas; en los años cuarenta y cincuenta, los perseguidos como consecuencia de la Segunda guerra mundial; en los años sesenta, el proceso de descolonización supuso numerosos refugiados; en los años ochenta y noventa, hubo numerosos desplazados por guerras, hambre y miseria, provocando desplazamientos en numerosos lugares del mundo (guerras en África, guerra de Yugoslavia, conflictos en países árabes). Esta situación se ha visto agudizada por crecimientos demográficos desproporcionados en algunos países y el reparto desigual de la riqueza, que cada vez provoca una brecha más amplia entre unos países y otros ${ }^{4}$.

Inmigrantes y refugiados son dos realidades distintas, pero comparten un objetivo común: emprender una nueva vida en un lugar mejor. Sin embargo, unos huyen por motivos políticos y otros por razones económicas. El problema reside muchas veces en diferenciarlos, sobre todo cuando el país de origen es un lugar de conflicto y también de problemas económicos.

\footnotetext{
${ }^{4}$ MARTín ARRIBAS, J.J., Los Estados Europeos frente al desafío de los refugiados y el derecho de asilo, Madrid, Dykinson-Universidad de Burgos, 2000, p.26.
} 
Conviene clarificar la diferencia entre los términos 'refugiado' y 'migrante', ya que a veces se utilizan de manera indistinta, siendo su concepto diferente. $Y$ no se trata de una mera retórica de conceptos sino porque los resultados de la confusión entre la categoría de unos y otros incide en las medidas que se adopten al respecto (la devolución o expulsión de un refugiado puede conllevar una alta probabilidad de muerte cuando llegue de nuevo al país del que salió huyendo).

En primer lugar, los "migrantes" son quienes eligen trasladarse no a causa de una amenaza directa de persecución o muerte, sino principalmente para mejorar sus vidas al encontrar trabajo o educación, por reunificación familiar, o por otras razones. A diferencia de los refugiados, quienes no pueden volver a su país, los migrantes continúan recibiendo la protección de su gobierno ${ }^{5}$.

Un «inmigrante» es aquella persona que «inmigra», es decir, que llega a otro país para establecerse en él. Muchos de estos inmigrantes -los que no tienen documentación en regla-, pueden ser deportados y transportados de nuevo hacia su país de origen. Las causas de esta huida pueden ser muchas y variadas: desde pobreza a falta de empleo o búsqueda de otro futuro. Si optan por volver seguirán contando con la protección de su Gobierno.

Para los gobiernos esta distinción es importante. Los países tratan a los migrantes de conformidad con su propia legislación y procedimientos en materia de inmigración, mientras tratan a los refugiados aplicando normas sobre el asilo y la protección de los refugiados, que están definidas tanto en su legislación nacional, como en el derecho internacional. Los países tienen responsabilidades específicas hacia cualquier persona que solicite asilo en su territorio o en sus fronteras.

La emigración hacia Europa, en cualquiera de sus modalidades, es una realidad y seguirá siéndolo en el futuro. Las razones por las que las personas deciden trasladarse a la Unión Europea (UE) son de muy diversa índole. Algunas vienen para estudiar o investigar, otras para trabajar y otras para reunirse con sus familiares que ya viven en la UE. Al mismo tiempo, un número cada vez mayor de crisis mundiales, tanto naturales como provocadas por el hombre, han impulsado a muchas personas a abandonar su país de origen. De los aproximadamente 507 millones de personas que viven en la UE, en torno a 20 millones son ciudadanos de países no miembros de la UE ${ }^{6}$.

Una de las cuestiones problemáticas de la inmigración es que a veces se produce de forma irregular. Hay personas que entran legalmente con un visado de corta duración y a continuación alargan su estancia más allá de lo permitido. También puede ocurrir que otras entren y residan en un Estado miembro de la UE sin autorización, a veces incluso en contra de su voluntad.

\footnotetext{
5 EDWARDS, A., “¿'Refugiado' o 'Migrante’? ACNUR insta a usar el término correcto”. Disponible en: http://www.acnur.org/t3/noticias/noticia/refugiado-o-migrante-acnur-insta-a-usar-el-termino-correcto/

${ }^{6}$ Con el fin de apoyar los esfuerzos de sus Estados miembros por gestionar la inmigración de forma eficaz, la UE ofrece posibilidades de financiación en el ámbito de la integración de los ciudadanos de países no miembros de la UE y la repatriación de los inmigrantes irregulares. Por ejemplo, durante el periodo de 2014-2020, la UE habrá otorgado 3137 millones de euros, a través del Fondo de Asilo, Migración e Integración (FAMI), a favor de iniciativas de los Estados miembros para fomentar la gestión eficiente de los flujos migratorios. "Comprender las Políticas a través de la Unión Europea. Migración y asilo". Disponible en: < http://europa.eu/pol/pdf/flipbook/es/migration_es.pdf>.
} 
Las redes de contrabando y trata de seres humanos pueden explotar fácilmente a las personas sin papeles. El mercado del trabajo no declarado también atrae a la inmigración irregular. Para proteger a los más vulnerables y mantener la confianza de los ciudadanos en las políticas de inmigración hay que combatir la inmigración irregular en todas sus modalidades.

En una Unión Europea de 28 Estados miembros, en el que la mayoría de las fronteras interiores se han abolido y las personas pueden circular libremente, cada país por sí solo no puede gestionar la migración. La cooperación de los Estados miembros de la UE es esencial para gestionar mejor la migración. Al mismo tiempo, es fundamental sacar el mayor partido posible a la dimensión exterior de la política de migración y movilidad de la UE y estrechar la cooperación con nuestros vecinos y socios estratégicos ${ }^{7}$.

En segundo lugar, el término "refugiados" describe a personas que huyen de conflictos armados o persecución ${ }^{8}$. Con frecuencia, su situación es tan peligrosa e intolerable que deben cruzar fronteras internacionales para buscar seguridad en los países cercanos y, entonces, convertirse en 'refugiados' reconocidos internacionalmente, con acceso a la asistencia de los Estados, el ACNUR y otras organizaciones. Son reconocidos como tal, precisamente porque es muy peligroso para ellos volver su país y necesitan asilo en algún otro lugar. Para estas personas, la denegación del asilo tiene potencialmente consecuencias mortales $^{9}$.

El Derecho internacional define y protege a los refugiados. Los instrumentos jurídicos internacionales han sido varios. Como respuesta a las atrocidades de la II Guerra Mundial, la Declaración Universal de Derechos Humanos (1948) hace un alegato al derecho de asilo en su artículo 14 al mantener que "en caso de persecución, toda persona tiene derecho a buscar asilo, y a disfrutar de él, en cualquier país" sin que este derecho se pueda invocar contra una acción judicial originada por delitos comunes o por actos opuestos a los propósitos y principios de las Naciones Unidas. En la misma línea la Convención sobre el Estatuto de los Refugiados, aprobada en Ginebra el 28 de julio de 1951, y el Protocolo sobre el Estatuto de los Refugiados, firmado en Nueva York el 31 de enero de 1967, constituyen las dos disposiciones de referencia a nivel internacional respecto al derecho de asilo. También la Convención de la OUA por la que se regulan los aspectos específicos de problemas de los refugiados en África, de 1969, o la Declaración de Cartagena sobre los Refugiados, de 1984, continúan siendo la piedra angular de la moderna protección de los refugiados. Los principios legales que engloban han permeado innumerables leyes y costumbres internacionales,

\footnotetext{
${ }^{7}$ Para completar y armonizar las políticas nacionales de inmigración, la UE está creando un marco jurídico común, que contempla las condiciones de entrada y residencia para determinadas categorías de inmigrantes, como los estudiantes, los investigadores y los trabajadores, con el fin de simplificar sus procedimientos de admisión y de otorgarles los derechos que son comunes a toda la Unión. Por ejemplo, los ciudadanos de países no miembros de la UE que hayan residido legalmente en uno de sus Estados miembros durante cinco años, como mínimo, tienen derecho al estatuto de residentes de larga duración, que es común a toda la UE y que les otorga una serie de derechos económicos y sociales similares a los de los ciudadanos de la UE.

${ }^{8}$ El refugiado es alguien que fue forzado a huir de su país natal. En este sentido, los refugiados pueden pedir asilo en países europeos, un proceso que podría tardar años ya por motivos de raza o religión. Hasta que no consigue este estatus, estas personas son solicitantes de asilo.

9 EDWARDS, A., “¿'Refugiado' o 'Migrante’?, cit.
} 
regionales y nacionales. Todas estas previsiones tienen un punto en común: proteger al perseguido, dotándole de instrumentos jurídicos que le amparen.

La Convención de Ginebra, de 1951, define quién es un refugiado y delimita los derechos básicos que los Estados deben garantizar a los refugiados. Uno de los principios fundamentales establecidos en el Derecho internacional es que los refugiados no deben ser expulsados o devueltos a situaciones en las que su vida y libertad están en peligro.

Artículo 1 Definición del término «refugiado»

\begin{abstract}
A los efectos de la presente Convención, el término «refugiado» se aplicará a toda persona: Que, como resultado de acontecimientos ocurridos antes del $1 .^{\circ}$ de enero de 1951 y debido a fundados temores de ser perseguida por motivos de raza, religión, nacionalidad, pertenencia a determinado grupo social u opiniones políticas, se encuentre fuera del país de su nacionalidad y no pueda o, a causa de dichos temores, no quiera acogerse a la protección de tal país; o que, careciendo de nacionalidad y hallándose, a consecuencia de tales acontecimientos, fuera del país donde antes tuviera su residencia habitual, no pueda o, a causa de dichos temores, no quiera regresar a él ${ }^{10}$
\end{abstract}

En tercer lugar, por "asilo" puede entenderse una modalidad de protección internacional que se concede a las personas que huyen de sus países de origen a causa de un temor fundamentado a ser perseguido. La protección también se concede a las personas que corren un riesgo real de sufrir daños graves si regresan a su país de origen. La base esencial del derecho de asilo suele ser de tipo político y supervivencia física. En cambio, en la inmigración están más presentes las connotaciones de carácter económico por las desigualdades existentes entre los países de origen y el receptor.

El principio de no devolución - non refoulement - constituye la base de la institución del asilo tal como lo presenta la Convención de Ginebra, en su artículo 33, que imposibilita la expulsión o devolución de un refugiado en las fronteras de los territorios donde su vida o su libertad peligre por causa de su raza, religión, nacionalidad, pertenencia a determinado grupo social o de sus opiniones políticas, salvo los casos en los que el refugiado suponga un peligro para la seguridad del país o una amenaza para la comunidad en caso de delito grave.

\footnotetext{
${ }^{10}$ También hay que tomar en consideración dos normas adoptadas por el Consejo de la Unión: i) POSICIÓN COMÚN de 4 de marzo de 1996 definida por el Consejo, sobre la base del artículo K.3 del Tratado de la Unión Europea relativa a la aplicación armonizada de la definición del término «refugiado» conforme al artículo 1 de la Convención de Ginebra de 28 de julio de 1951 sobre el Estatuto de los Refugiados (96/196/JAI). Disponible en: http://www.acnur.org/t3/fileadmin/Documentos/BDL/2008/6033.pdf?view=1.; ii) Resolución del Consejo de 20 de junio de 1995 sobre las garantías mínimas para los procedimientos de asilo [Diario Oficial C 274 de 19.09.1996]. Disponible en: http://eur-lex.europa.eu/legal-content/ES/TXT/?uri=URISERV\%3Al33103. (Acceso el 11.06.2016).

El Convenio de Ginebra también establece qué personas quedan excluidas: a) las personas que ya reciben protección o asistencia de Naciones Unidas; b) Las personas protegidas por el país de residencia, c) Los criminales y vulneradores de la Carta de Naciones Unidas (porque hayan cometido delitos contra la paz, delitos de guerra o delitos contra la humanidad; las personas que hayan cometido grave delito común; c) Las personas que hayan cometido delito grave común. (artículo 1.D, E y F de la convención de Ginebra).
} 
Según la Convención de Ginebra (en sus artículo 32 y 33.2), en el caso de que el individuo que constituye una amenaza para la seguridad o el orden público reúna los requisitos necesarios para ser considerado como refugiado puede realizarse una ponderación que en caso de ser la amenaza muy acusada puede llegar a justificar la devolución al país de origen del refugiado. En cambio dicha devolución no es posible cuando el sujeto en cuestión cumpla los requisitos para ser amparado por la protección subsidiaria, al menos, cuando exista un riesgo real de que el afectado sea sometido a torturas o tratos inhumanos o degradantes.

En los Estados Europeos, ya desde el inicio de este tercer milenio, se había puesto de manifiesto que un gran número de emigrantes económicos solicitaba asilo, ya que resultaba más ventajoso en Europa, lo que había generado el fenómeno denominado "abuso del derecho de asilo" ${ }^{11}$.

Como señala Díez de Velasco, en el actual estadio de evolución del Derecho internacional, "el asilo territorial tiene su fundamento en la competencia que ejerce el Estado sobre su territorio"12 de manera que el derecho de asilo se configura como una potestad del Estado que lo concede y no como una prerrogativa de la persona que lo solicita. Por ello, parece que

en puridad no se trata de uno de los derechos humanos internacionalmente protegibles, sino de un mecanismo protector frente a la violación de determinados derechos del hombre; concretamente, del derecho a no ser perseguido por motivos políticos, religiosos, raciales, por luchar contra el colonialismo o por cualquier otro motivo distinto de la comisión de un delito común o de un delito contra la paz, de guerra o contra la humanidad ${ }^{13}$.

En definitiva, como apunta el profesor Mariño, aunque la evolución del actual Derecho internacional pueda ir en la dirección de reconocer un derecho subjetivo internacional a recibir asilo, lo cierto es que actualmente no se reconoce tal derecho ejercitable frente a un Estado determinado ${ }^{14}$.

\footnotetext{
${ }^{11}$ Como acertadamente sostiene Martín Arribas, esta denominación se había acuñado como consecuencia de que, en la práctica, muchos ciudadanos europeos intentaban evitar un complicado proceso burocrático, además de que sorteaban las limitaciones o restricciones que los Estados europeos imponían por motivos esencialmente económicos. MARTíN ARRIBAS, J.J., Los Estados Europeos frente al desafío de los refugiados y el derecho de asilo, cit., p.30, nota 27. Los inmigrantes económicos no pueden beneficiarse de la normativa que se ha establecido a favor de los perseguidos políticos, raciales o religiosos, aunque como sabemos, las condiciones a las que pueden acceder son tan atractivas que en numerosos casos, los inmigrantes pretenden obtener el estatus de refugiado político disimulando su motivación inicial de su desplazamiento e inventándose una historia de persecución en la que se presentan como víctimas. En el intento de burlar la normativa, otra modalidad es la de intentar falsificar pasaportes de nacionalidades de países que sí están en situación de persecución política. En este sentido, en 2015, la Agencia Europea de Fronteras (FRONTEX) alertaba sobre la existencia de un tráfico de pasaportes sirios falsos para facilitar la entrada de inmigrantes en la Unión Europea. Disponible en: < http://www.abc.es/internacional/20150901/abci-pasaportes-falsos-siria201509011111.html>. (Acceso el 09.06.2016).

${ }^{12}$ DÍEZ DE VELASCO, M., Instituciones de Derecho Internacional público, T.I, 12åed., Madrid, Tecnos, 1999, p.514.

${ }^{13}$ MARTÍN ARRIBAS, J.J., Los Estados Europeos frente al desafío de los refugiados y el derecho de asilo, cit., p.31.

${ }^{14}$ MARIÑO MENÉNDEZ, F., “Los derechos de los extranjeros en el Derecho Internacional” en Capítulo IV de Derecho de extranjería, asilo y refugio, F. Mariño Menéndez y otros, Madrid, Ministerio de Asuntos Sociales, 1996, pp.505-526.
}

Revista do Direito [ISSN 1982-9957]. Santa Cruz do Sul, v. 3, n. 50, p. 138-174, set./dez. 2016. https://online.unisc.br/seer/index.php/direito/index 
Desde una perspectiva técnico-jurídica, conviene no confundir a los refugiados con los solicitantes de asilo. Refugiado, en el Derecho internacional, designa a toda persona que busca refugio o amparo ante una persecución o un peligro físico, en la embajada o en el territorio de un Estado diferente a aquel del que es súbdito. Suele implicar una protección temporal contra un peligro inmediato, lo que lleva a distinguirlo del reconocimiento del derecho de asilo porque conlleva una protección definitiva.

\section{LA POLÍTICA DE ASILO EN LA UNIÓN EUROPEA}

La legislación aplicable al asilo, la gestión de fronteras y la inmigración en el marco del Derecho de la Unión Europea (UE) y del Convenio Europeo de Derechos Humanos (CEDH) es compleja. Para tener una idea, baste considerar que el Derecho de la UE contempla unas veinte categorías diferentes de nacionales de terceros países, cada una de las cuales tiene unos derechos distintos que varían según los vínculos de unión con los Estados miembros de la UE, o que derivan de su necesidad de protección especial. En algunos casos, como el de los solicitantes de asilo, el Derecho de la UE contiene un amplio conjunto de normas ${ }^{15}$.

El artículo 2 del Tratado de la Unión Europea establece que:

La Unión se fundamenta en los valores de respeto de la dignidad humana, libertad, democracia, igualdad, Estado de Derecho y respeto de los derechos humanos, incluidos los derechos de las personas pertenecientes a minorías. Estos valores son comunes a los Estados miembros en una sociedad caracterizada por el pluralismo, la no discriminación, la tolerancia, la justicia, la solidaridad y la igualdad entre mujeres y hombres ${ }^{16}$.

Por tanto, la UE parte de que el respeto a los derechos humanos es uno de los valores en los que se fundamenta. Sin embargo, en relación al tema que estamos analizando, ni el Tratado de Funcionamiento de la Unión Europea ni la Carta de los Derechos Fundamentales de la Unión Europea proporcionan una definición de los términos «asilo» $y$ «refugiado» ${ }^{17}$. Ambos instrumentos se refieren específicamente a la Convención de Ginebra de 28 de julio de 1951 y a su Protocolo de 31 de enero de 1967.

\footnotetext{
${ }^{15}$ Vid. Manual de Derecho Europeo sobre asilo, fronteras inmigración. Agencia de los Derechos Fundamentales de la Unión Europea, 2014. Disponible en: < http://fra.europa.eu/sites/default/files/handbook-law-asylummigration-borders-2nded_es.pdf $>$. (Acceso el 15.06.2016).

${ }^{16}$ Tratado de la Unión Europea. Versión consolidada. Disponible en: < http://www.boe.es/doue/2010/083/Z00013-00046.pdf>. (Acceso el 15.06.2016).

${ }^{17}$ Los fundamentos jurídicos pueden encontrarse en: i) artículo 67, apartado 2, y artículo 78 del Tratado de Funcionamiento de la Unión Europea; ii) Artículo 18 de la Carta de los Derechos Fundamentales de la Unión Europea.
} 
La política de la UE en materia de asilo tiene por objeto armonizar los procedimientos de asilo de los Estados miembros mediante la instauración de un sistema común de asilo, con miras a ofrecer un estatuto apropiado a todo nacional de un tercer país que necesite protección internacional y a garantizar el respeto del principio de no devolución.

Hasta ahora, nuestra política de asilo conformaba un todo defectuoso e incompleto. Las sorprendentes diferencias en los resultados de las solicitudes de asilo en el conjunto de la UE, las condiciones materiales en las que se acoge a los solicitantes y los derechos procesales que se les otorgan, afectaban a la credibilidad y la eficacia de nuestro sistema de asilo. Esto es injusto tanto para los solicitantes de asilo como para los países que los acogen, y es una de las principales razones por las que un pequeño número de nuestros estados miembros reciben una parte desproporcionadamente grande del total de solicitantes: el 70 por ciento de las solicitudes se presentan en sólo cinco estados miembros, entre ellos, algunos de los grandes, como Francia, Alemania y Reino Unido, pero también de los más pequeños, como Bélgica y Suecia ${ }^{18}$.

\subsection{Instrumentos jurídico-políticos}

La Unión Europea está haciendo frente al reto que supone la llegada de migrantes, refugiados y solicitantes de asilo utilizando tanto las normas de Derecho Internacional de los derechos humanos como las derivadas de sus Instituciones europeas.

En el Derecho de la UE hay un antes y un después tras el Tratado de la UE. El antes es porque previamente la Comunidad carecía de competencias para abordar la problemática de los refugiados y de los solicitantes de asilo. El Acta Única Europea, que entró en vigor en julio de 1985, introduce en el Tratado de la Comunidad Económica europea un nuevo artículo $8^{a}$ por el que la Comunidad se comprometía a adoptar medidas destinadas a establecer progresivamente, con fecha límite de 31 de diciembre de 1992, el mercado interior, es decir, un espacio sin fronteras interiores en el que la libre circulación de mercancías, personas, servicios y capitales quedara garantizada según las disposiciones del Tratado. El Tratado de la Unión Europea -TUE- apostaba por la profundización en la supresión de las fronteras interiores y eliminar los límites para crear un espacio de libertad, seguridad y justicia, lo que se consiguió a partir de la entrada en vigor del Tratado de Maastricht, de 1 de noviembre de $1993^{19}$. A partir de entonces y hasta 1999, año en que se firma el Tratado de Amsterdam, se van armonizando las políticas estatales relativas al derecho de asilo, comunitarizando

\footnotetext{
${ }^{18}<$ La política de asilo de la UE ya es una realidad http://www.larazon.es/opinion/tribuna/la-politica-de-asilode-la-ue-ya-es-una-reali-BE2776210?sky=Sky-Junio-2016\#Ttt1CbyeUvDvd7I2>.

${ }^{19}$ Entre los contenidos jurídicos del Tratado de Maastricht, en el Título VI del Tratado se confería fuerza vinculante a la obligación estatal de cooperar en una serie de materias considerados de interés común, entre las que se incluía expresamente el derecho de asilo, las normas que rigen el cruce de personas por las fronteras exteriores de los Estados miembros y la práctica de controles sobre esas personas, la política de inmigración y la política relativa a nacionales de terceros Estados sobre determinadas materias (cooperación en los ámbitos de la justicia y los asuntos de interior). MARTín ARRIBAS, J., Los Estados Europeos frente al desafío de los refugiados y el derecho de asilo, cit., p.121.
} 
el derecho de asilo como un derecho de mínimos y vinculándolo a materias conexas tales como visados, inmigración y otras políticas relacionadas con la libre circulación de personas ${ }^{20}$.

La necesidad de conseguir un espacio de libertad, de seguridad y de justicia suponía la realización de esfuerzos adicionales en la coordinación y la realización efectiva de los controles de las fronteras externas a la Unión Europea. El Tratado de Amsterdam establece un régimen jurídico basado en cuatro pilares: i) la creación de un nuevo Título en el Tratado de la Comunidad sobre visados, asilos, inmigración y otras políticas relacionadas con la libre circulación de personas; ii) el mantenimiento de una serie de disposiciones relativas a la cooperación judicial y policial en materia penal, así como la prevención y la lucha contra el racismo y la xenofobia; iii) la incorporación del acervo Schengen $^{21}$ al marco de la UE mediante un protocolo especial; iv) un articulado que permitiera flexibilizar este régimen jurídico. El Tratado, teniendo presente que suele tratarse de situaciones que normalmente desbordan los efectivos humanos y los recursos físicos y económicos de los que disponen el país al que solicitan protección, ya contempla normas que, de acuerdo con la necesaria

\footnotetext{
${ }^{20}$ La política europea de asilo arranca con el Tratado de Ámsterdam de 1997 y ha producido un extenso elenco de normas comunitarias que han debido ser incorporadas al ordenamiento jurídico interno de los países miembros mediante los oportunos cambios legislativos que, en algunos casos, son de gran entidad. De entre estas normas destacan, por afectar al núcleo de todo sistema de asilo, la Directiva 2004/83/CE, del Consejo, de 29 de abril, por la que se establecen normas mínimas relativas a los requisitos para el reconocimiento y el estatuto de nacionales de terceros países o apátridas como refugiados o personas que necesitan otro tipo de protección internacional y al contenido de la protección concedida. Disponible en: <http://eurlex.europa.eu/legal-content/ES/TXT/?uri=URISERV\%3Al33176>. (Acceso el 03.03.2016). Esta Directiva es la que define las condiciones para obtener el estatuto de refugiado y el estatuto de beneficiario de una protección internacional; la Directiva 2005/85/CE, del Consejo, de 1 de diciembre, sobre normas mínimas para los procedimientos que deben aplicar los Estados miembros para conceder o retirar la condición de refugiado. Disponible en: <https://www.boe.es/doue/2005/326/L00013-00034.pdf > (Acceso el 04.03.2016); y el Capítulo $V$ de la Directiva 2003/86/CE, del Consejo, de 22 de septiembre, sobre el derecho de reagrupación familiar relativo a los refugiados. Disponible en: <eur-lex.europa.eu > EUROPA > EU law and publications > EUR-Lex >. (Acceso el 02.03.2016). De la naturaleza misma de las normas mínimas se desprende que los Estados miembros tienen competencia para introducir o mantener disposiciones más favorables para las personas de terceros países o apátridas que pidan protección internacional a un Estado miembro, siempre que tales normas sean compatibles con lo dispuesto en las Directivas comunitarias. Asimismo, también hay que tener en cuenta criterios que se desprenden de la doctrina y de la jurisprudencia de los tribunales en materia de asilo.

${ }^{21}$ El espacio y la cooperación Schengen se basan en el Tratado Schengen de 1985. El espacio Schengen representa un territorio donde está garantizada la libre circulación de las personas. Los Estados que firmaron el Tratado han suprimido todas las fronteras interiores y en su lugar han establecido una única frontera exterior. Dentro de esta se aplican procedimientos y normas comunes en lo referente a los visados para estancias cortas, las solicitudes de asilo y los controles fronterizos. Al mismo tiempo, se han intensificado la cooperación y la coordinación entre los servicios policiales y las autoridades judiciales para garantizar la seguridad dentro del espacio Schengen. La cooperación Schengen se integró en el Derecho de la Unión Europea por el Tratado de Ámsterdam en 1997. No obstante, todos los países que participan en la cooperación Schengen no son miembros del espacio Schengen, bien porque no deseaban suprimir los controles en sus fronteras, bien porque no reúnen todavía las condiciones requeridas para aplicar el acervo Schengen. Las principales normas aprobadas dentro del marco Schengen incluyen: i) la supresión de los controles de personas en las fronteras interiores; ii) un conjunto de normas de común de aplicación a las personas que cruzan las fronteras exteriores de los Estados miembros de la UE; iii) la armonización de las condiciones de entrada y de visados para las cortas estancias; iv) una mejora de la coordinación policial (incluidos los derechos de vigilancia y persecución transfronterizas); v) el refuerzo de la cooperación judicial a través de un sistema de extradición más rápido y una mejor transmisión de la ejecución de sentencias penales; vi) la creación del Sistema de Información Schengen (SIS). Disponible en: <http://eur-lex.europa.eu/legal-content/ES/TXT/?uri=URISERV\%3AI33020>.
} 
solidaridad entre los Estados miembros, impliquen una coordinación con los órganos administrativos estatales competentes en la acogida de desplazados y un reparto equitativo de las cargas económicas que ello suponga.

El enfoque que la UE ha tenido con respecto a los refugiados ha sido no exactamente el de ofrecer una solución particularizada de cada solicitante de asilo, sino más bien la situación del grupo de refugiados respetando el principio de no devolución; además, se parte de la premisa de que no es un problema individualizado de un Estado miembro, sino de todos, por lo que se coopera repartiendo equitativamente las cargas que esto suponga. Es decir, se comunitarizan aspectos que, hasta la entrada en vigor del Tratado de Amsterdam, se regulaban exclusivamente por los derechos internos $^{22}$.

A su vez, los Derechos internos de los Estados miembros de la UE han tenido que ajustarse a un doble contenido jurídico: en primer lugar, el Derecho que integra las normas del Derecho internacional (Convención de Ginebra de 1951 y Protocolo de Nueva York de 1967, que regulan el estatuto del refugiado). Pero hay que dejar constancia que no determinan auténticos derechos para los beneficiarios. Sólo incluyen en su articulado cláusulas de tipo formal con las que se tiende a conceder, a los extranjeros que obtiene tal estatuto, derechos muy próximos a los que reciben otros extranjeros o los que disfrutan los nacionales del estado de acogida, respetando los derechos adquiridos). En segundo lugar, las normas de la UE, entre las que cabe destacar el ya citado Convenio de Schengen y el Convenio de Dublín ${ }^{23}$. El Convenio de Dublín se utiliza para determinar a qué Estado le corresponde examinar una solicitud de asilo para lo que se tiene en cuenta un conjunto de criterios, tales como la reunificación familiar, permiso de residencia o visado vigente, cruce irregular de una frontera estatal. Comparando lo que aporta el Derecho de la UE con respecto al

\footnotetext{
${ }^{22}$ MARTín ARRIBAS, J., Los Estados Europeos frente al desafío de los refugiados y el derecho de asilo, cit., p.130.

${ }^{23}$ La Convención de Dublín es una ley de la UE para racionalizar los procesos de postulación de solicitantes de asilo de acuerdo a la Convención de Ginebra. Intenta clarificar cuál estado miembro es responsable de una solicitud particular, y asegurar que al menos un Estado miembro tramite la solicitud. Por regla general, suele ser el Estado miembro en donde el solicitante ingresó por primera vez en la Unión Europea. La Convención fue firmada en Dublín, Irlanda el 15 de junio de 1990, y entró en vigencia el 1 de septiembre de 1997 en los primeros doce estados firmantes (Alemania, Bélgica, Dinamarca, España, Francia, Grecia, Irlanda, Italia, Luxemburgo, los Países Bajos, Portugal, y el Reino Unido), el 1 de octubre de 1997 por Austria y Suecia, y el 1 de enero de 1998 por Finlandia. Aunque el convenio solo estaba abierto a la adhesión de los Estados miembros de la Comunidad Europea (CE), Noruega e Islandia - Estados no miembros - cerraron acuerdos con la CE para aplicar las disposiciones del Convenio de Dublín en sus territorios En 2003, la Convención de Dublín fue reemplazada por el Reglamento № 343/2003, Ilamado Dublín II. En 2008, la Comisión Europea propuso enmendarlo, creando una oportunidad para reformar el «sistema de Dublín». En 2013, fue acordado el Reglamento Dublín III por el Parlamento Europeo y el Consejo de la UE —derogando Dublín II-. Vid. REGLAMENTO (UE) No 604/2013 DEL PARLAMENTO EUROPEO Y DEL CONSEJO de 26 de junio de 2013 por el que se establecen los criterios y mecanismos de determinación del Estado miembro responsable del examen de una solicitud de protección internacional presentada en uno de los Estados miembros por un nacional de un tercer país o un apátrida (Texto refundido). Disponible en: < https://www.boe.es/doue/2013/180/L0003100059.pdf>. (Acceso el 11.06.2016). En agosto de 2015, la masiva llegada de refugiados colapsa la burocracia en países fronterizos como Grecia, lo que desembocó en que Alemania decidiera suspender de facto la aplicación del Convenio Dublín III y tramitar las solicitudes de asilo, con el fin de agilizar el proceso.
}

Revista do Direito [ISSN 1982-9957]. Santa Cruz do Sul, v. 3, n. 50, p. 138-174, set./dez. 2016. https://online.unisc.br/seer/index.php/direito/index 
Derecho internacional en relación a los refugiados, puede afirmarse, siguiendo a Martín Arribas, "que introduce garantías adicionales que benefician a los solicitantes de asilo" ${ }^{24}$.

En 2001, el Tratado de Niza dispuso que, durante los cinco años siguientes a su entrada en vigor, el Consejo debía adoptar medidas en determinados ámbitos, en concreto criterios y mecanismos para determinar qué Estado miembro debía encargarse de examinar una solicitud de asilo presentada en uno de los Estados miembros por un nacional de un tercer país, así como una serie de normas mínimas (acogida de los solicitantes de asilo, estatuto de los refugiados, procedimientos).

El Tratado de Lisboa, de 2007, ha supuesto una innovación ${ }^{25}$, ya que transforma en política común las medidas en materia de asilo. Su objetivo no es solo el establecimiento de normas mínimas, sino también la creación de un sistema común que incluya estatutos y procedimientos uniformes. Este sistema debe comprender los siguientes elementos: i) un estatuto uniforme de asilo; ii) un estatuto uniforme de protección subsidiaria; iii) un sistema común de protección temporal; iv) procedimientos comunes para conceder o retirar el estatuto uniforme de asilo o la protección subsidiaria; v) criterios y mecanismos para determinar el Estado miembro responsable de examinar una solicitud; vi) normas relativas a las condiciones de acogida; vii) asociación y cooperación con terceros países.

La creciente llegada de refugiados demandantes de asilo ha hecho que la UE adoptara un conjunto de importantes reformas legislativas que facilitarán la garantía de los derechos de las personas que huyen de persecuciones y que dotará a la Unión de un Sistema Europeo Común de Asilo. La Comisión Europea, el Parlamento Europeo y el Consejo han trabajado durante años para definir un marco jurídico general aplicable al tratamiento de los solicitantes de asilo. El reciente acuerdo sobre la reforma del sistema de asilo de la UE es un importante logro, un reconocimiento a la voluntad política y la determinación de todos quienes, durante casi cinco años, participaron en negociaciones a menudo difíciles. Nos sirve para recordar que la UE se basa en valores que consagran el respeto de los derechos humanos y el Estado de Derecho y demuestra que, incluso en tiempos de crisis económica, la promoción del derecho de asilo centra los esfuerzos de la Unión para la creación de un espacio de libertad y justicia. Los sucesivos programas adoptados por el Consejo Europeo han influido profundamente en la aplicación de la política europea en materia de asilo. El Programa de Estocolmo, aprobado por el Consejo Europeo el 10 de diciembre de 2009 para el período 2010-2014, reafirma «el objetivo de establecer un espacio común de protección y solidaridad que se base en un procedimiento común de asilo y un estatuto uniforme para las personas a las que se concede protección internacional». Destaca, en particular, la necesidad de promover una verdadera solidaridad con los Estados miembros sometidos a presiones específicas y el importante papel que debe desempeñar la Oficina Europea de Apoyo al Asilo -EASO-, creada en 2010, para

\footnotetext{
${ }^{24}$ MARTÍN ARRIBAS, J., Los Estados Europeos frente al desafío de los refugiados y el derecho de asilo, cit., p.322.

${ }^{25}$ TRATADO DE LISBOA POR EL QUE SE MODIFICAN EL TRATADO DE LA UNIÓN EUROPEA Y EL TRATADO CONSTITUTIVO DE LA COMUNIDAD EUROPEA (2007/C 306/01). Disponible en: < https://www.boe.es/legislacion/enlaces/documentos/ue/Trat_lisboa.pdf>.
} 
reforzar la cooperación entre Estados miembros en este ámbito y ayudarles a abordar situaciones críticas $^{26}$.

La política de asilo en la UE ha supuesto que los Estados miembros han asumido unos derechos y obligaciones en esta materia de protección de los derechos de los refugiados y de los solicitantes de asilo. Estos compromisos abarcan obligaciones tales como la de la colaboración, la vigilancia, la de información, la de no expulsión, la no devolución, la solución por medios pacíficos de las controversias, políticas para controlar la entrada y la residencia de estos ciudadanos (régimen de tránsito aeroportuario, cooperación consular local en materia de visados, la detección de documentación falsa y otros.

En respuesta a la tragedia humanitaria que se abatía sobre el Mediterráneo, la Comisión adoptó, en mayo de 2015, una Agenda Europea de Migración destinada a fortalecer la política común de asilo $^{27}$. El Sistema Europeo Común de Asilo (SECA) ${ }^{28}$ sigue unas determinadas fases de tramitación y se apoya en unas Directivas concretas, que son las siguientes:

i) El proceso de solicitud de asilo es ahora similar en toda la Unión Europea (UE). Directiva 2005/85/CE del Consejo, de 1 de diciembre de 2005, sobre normas mínimas para los procedimientos que deben aplicar los Estados miembros para conceder o retirar la condición de refugiado. Esta Directiva sobre procedimientos de asilo revisada pretende facilitar la adopción de decisiones más justas, rápidas y acertadas. Los solicitantes de asilo con necesidades especiales recibirán la

\footnotetext{
${ }^{26}$ El Reglamento (UE) no 439/2010 establece la creación de una Oficina Europea de Apoyo al Asilo (EASO). La EASO es una agencia de la Unión Europea (UE) que opera desde 2011. Sus funciones son: impulsar la cooperación entre Estados miembros en materia de asilo; apoyar a los Estados miembros cuyos sistemas de asilo y recepción estén sujetos a presiones especiales; mejorar la aplicación del Sistema Europeo Común de Asilo (SECA). Disponible en: http://eur-lex.europa.eu/legal-content/ES/TXT/?uri=URISERV\%3Ajl0022. (Acceso el 14.06.2016).

${ }^{27}$ Concretamente, mediante la puesta en marcha de las siguientes medidas:

-Decisión (UE) 2015/1601 del Consejo, de 22 de septiembre de 2015, por la que se establecen medidas provisionales en el ámbito de la protección internacional en beneficio de Italia y Grecia;

-Decisión (UE) 2015/1523 del Consejo, de 14 de septiembre de 2015, relativa al establecimiento de medidas provisionales en el ámbito de la protección internacional en favor de Italia y Grecia;

-Conclusiones de los representantes de los Gobiernos de los Estados miembros, reunidos en el seno del Consejo, sobre el reasentamiento mediante programas multilaterales y nacionales de 20000 personas claramente necesitadas de protección internacional, de 20 de julio de 2015.

-Propuesta de Reglamento del Parlamento Europeo y del Consejo por el que se establece un mecanismo de crisis en materia de reubicación y por el que se modifica el Reglamento (UE) № 604/2013 del Parlamento Europeo y del Consejo, de 26 de junio de 2013, por el que se establecen los criterios y mecanismos de determinación del Estado miembro responsable del examen de una solicitud de protección internacional presentada en uno de los Estados miembros por un nacional de un tercer país o un apátrida (COM(2015) 450); -Propuesta de Reglamento del Parlamento Europeo y del Consejo por el que se establece una lista común de la UE de países seguros a los efectos de la Directiva 2013/32/UE del Parlamento Europeo y del Consejo sobre procedimientos comunes para la concesión o la retirada de la protección internacional, y por el que se modifica la Directiva 2013/32/UE (COM(2015) 452). Vid. "La Política de Asilo en la UE". Disponible en: http://www.europarl.europa.eu/ftu/pdf/es/FTU_5.12.2.pdf. (Acceso el 14.06.2016).

${ }^{28}$ Vid. "Un sistema común europeo de asilo". http://ec.europa.eu/dgs/home-affairs/e-library/docs/ceas-factsheets/ceas_factsheet_es.pdf. (Acceso el 10.06.2016).
} 
asistencia necesaria para ofrecer las explicaciones que respaldan su demanda; se intensificará la protección de los menores no acompañados y de las víctimas de tortura ${ }^{29}$.

ii) Las impresiones dactilares de cada solicitante se envían a una base de datos llamada Eurodac (Reglamento Eurodac). El Reglamento Eurodac ${ }^{30}$ revisado proporcionará a los cuerpos de seguridad acceso a la base de datos de impresiones dactilares de solicitantes de asilo en circunstancias estrictamente limitadas y con el fin de prevenir, detectar o investigar los delitos más graves como los de asesinato o terrorismo. Esos datos se utilizan, junto con otros criterios, para determinar el país responsable de tramitar la solicitud de asilo (Reglamento de Dublín) Los solicitantes de asilo se benefician de una serie de condiciones materiales de acogida, como alojamiento y alimentos. La Directiva sobre condiciones de acogida revisada garantiza la existencia de condiciones materiales de acogida (por ejemplo, alojamiento) humanitarias para los solicitantes de asilo en toda la UE y el total respeto de los derechos fundamentales de los interesados ${ }^{31}$. Además,

\footnotetext{
${ }^{29}$ Sobre esta Directiva hay que tener presente la Sentencia del Tribunal de Justicia (Gran sala) de 6 de mayo de 2008, Asunto C 133/06, Parlamento Europeo contra Consejo de la Unión Europea, que dispone: “Anular los artículos 29, apartados 1 y 2, y 36, apartado 3, de la Directiva 2005/85/CE del Consejo, de 1 de diciembre de 2005, sobre normas mínimas para los procedimientos que deben aplicar los Estados miembros para conceder o retirar la condición de refugiado". Disponible en: <. http://eur-lex.europa.eu/legalcontent/ES/TXT/?uri=CELEX\%3A62006CJ0133>. (Acceso el 07.06.2016).

${ }^{30}$ Reglamento (CE) no 2725/2000 del Consejo, de 11 de diciembre del 2000, relativo a la creación del sistema «Eurodac» para la comparación de las impresiones dactilares para la aplicación efectiva del Convenio de Dublín. El Sistema Eurodac se regula mediante el citado Reglamento por el que se crea un sistema de comparación de las impresiones dactilares de los solicitantes de asilo y algunas categorías de inmigrantes irregulares. Este sistema facilitará la aplicación del Reglamento Dublín II, que permite determinar qué país de la Unión Europea (UE) es responsable del examen de una solicitud de asilo. El sistema «Eurodac» permite a los países de la Unión Europea (UE) ayudar a identificar a los solicitantes de asilo y a las personas interceptadas en relación con el cruce irregular de las fronteras exteriores de la Unión. Comparando sus huellas, los países de la UE pueden comprobar si un solicitante de asilo o un extranjero presente ilegalmente en su territorio ya ha solicitado asilo en otro país de la UE, o si un solicitante de asilo ha entrado irregularmente en el territorio de la Unión. Se compone de una unidad central gestionada por la Comisión Europea, de una base central informatizada de datos dactiloscópicos, y de medios electrónicos de transmisión entre los países de la UE y la base de datos central. Además de las huellas, los datos transmitidos por los países de la UE incluyen lo siguiente: i) el país de la UE de origen; ii) el sexo de la persona; iii) el lugar y fecha de la solicitud de asilo o la interceptación de la persona; iv) el número de referencia; v) la fecha de toma de impresiones dactilares; vi) la fecha de transmisión de datos a la unidad central. Se toman los datos de toda persona mayor de 14 años y se envían a la unidad central a través de los puntos de acceso nacionales. Reglamento (UE) $n^{\circ} 603 / 2013$ del Parlamento Europeo y del Consejo, de 26 de junio de 2013, relativo a la creación del sistema «Eurodac» para la comparación de las impresiones dactilares para la aplicación efectiva del Reglamento (UE) n 604/2013, por el que se establecen los criterios y mecanismos de determinación del Estado miembro responsable del examen de una solicitud de protección internacional presentada en uno de los Estados miembros por un nacional de un tercer país o un apátrida, y a las solicitudes de comparación con los datos de Eurodac presentadas por los servicios de seguridad de los Estados miembros y Europol a efectos de aplicación de la ley, y por el que se modifica el Reglamento (UE) n 1077/2011, por el que se crea una Agencia europea para la gestión operativa de sistemas informáticos de gran magnitud en el espacio de libertad, seguridad y justicia (refundición) (aplicable desde el 20 de Julio de 2015).

${ }^{31}$ El Comité DESC ha manifestado su preocupación en los casos de las personas que siguen retenidas en los centros de internamiento pendientes de expulsión en condiciones de hacinamiento, sin acceso a la información y a servicios adecuados de asistencia social, médica o legal. Así, en cuanto a España, el Comité insta al Estado español "a dar pleno efecto a la nueva normativa para mejorar las condiciones de vida en los centros de retención para los extranjeros pendientes de expulsión, especialmente en términos de su acceso a servicios adecuados de asistencia sanitaria, social, legal y médica". <http://eur-lex.europa.eu/legalcontent/ES/TXT/?uri=CELEX\%3A62006CJ0133>.
}

Revista do Direito [ISSN 1982-9957]. Santa Cruz do Sul, v. 3, n. 50, p. 139-174, set./dez. 2016. https://online.unisc.br/seer/index.php/direito/index 
asegura que las medidas de detención solo se apliquen como último recurso. Directiva 2013/33/UE del Parlamento Europeo y del Consejo, de 26 de junio de 2013, por la que se aprueban normas para la acogida de los solicitantes de protección internacional (refundición) (aplicable desde el 21 de julio de 2015)

iii) Con la ayuda de un intérprete, los solicitantes de asilo son entrevistados por un agente con formación jurídica de la UE para determinar si reúnen las condiciones necesarias para inscribirse en la categoría de refugiados o recibir protección subsidiaria. (Directiva sobre requisitos y Directiva sobre procedimientos de asilo); Aquí se abren dos posibilidades: a) Puede concederse al interesado bien el estatuto de refugiado, bien protección subsidiaria que otorga al interesado ciertos derechos como el acceso a un permiso de residencia, al mercado de trabajo y a atención sanitaria (Directiva sobre requisitos; b) No se concede asilo al solicitante en «primera instancia», pero esa denegación puede ser recurrida ante los tribunales. Aquí, a su vez, hay otras dos opciones: Confirmación por el tribunal de la decisión denegatoria adoptada en «primera instancia», tras lo que el solicitante puede ser devuelto a su país de origen o de tránsito. O bien, Revocación por el tribunal de la resolución denegatoria «en primera instancia".

Además de la Convención de 1951 y el Protocolo de 1967 y del Estatuto de la Oficina del Alto Comisionado de Las Naciones Unidas para los Refugiados, junto al a nivel regional europeo, existen una serie de acuerdos, convenciones y otros instrumentos regionales relativos a los refugiados, especialmente en África, América y Europa. Esos instrumentos regionales versan sobre cuestiones como la concesión del asilo, los documentos de viaje y las facilidades de viaje, etc. Algunos de ellos contienen también una definición del término "refugiado" o de las personas con derecho a invocar el asilo.

En América Latina, el problema del asilo territorial y diplomático ha sido tratado en

Un conjunto de instrumentos regionales, entre los que figuran el Tratado sobre Derecho Penal Internacional (Montevideo, 1889); el Acuerdo sobre Extradición, (Caracas, 1911); la Convención sobre Asilo (La Habana, 1928); la Convención sobre Asilo Político (Montevideo, 1933); la Convención sobre Asilo Diplomático (Caracas, 1954); y la Convención sobre Asilo Territorial (Caracas, 1954) $)^{32}$.

\footnotetext{
${ }^{32}$ Un instrumento regional más reciente es la Convención que rige los aspectos inherentes a los problemas de los refugiados de África, adoptada el 10 de septiembre de 1969 por la Asamblea de Jefes de Estado y de Gobierno de la Organización de la Unidad Africana. Esta Convención contiene una definición del término "refugiado" que comprende dos partes, la primera de las cuales es idéntica a la definición del Protocolo de 1967 (es decir, la definición de la Convención de 1951 sin la fecha límite ni la limitación geográfica). En su segunda parte dispone que el término "refugiado" se aplica también a "toda persona que, a causa de una agresión, una ocupación o una dominación extranjera, o acontecimientos que perturben gravemente el orden público en una parte o en la totalidad de su país de origen o del país de su nacionalidad, está obligada a abandonar su residencia habitual para buscar refugio en otro lugar fuera de su país de origen o del país de su nacionalidad." Vid. Manual y Directrices sobre procedimientos y criterios para determinar la condición de refugiado, en virtud de la Convención de 1951 y el Protocolo de 1967 sobre el estatuto de los refugiados.
} 


\subsection{Dificultades del acceso al derecho de asilo}

Los refugiados y migrantes tiene derechos que están reconocidos en diversas Declaraciones y Convenios de carácter universal e internacional. El artículo 14 de la Declaración Universal de los Derechos Humanos establece que: "En caso de persecución, toda persona tiene derecho a buscar asilo y a disfrutar de él en cualquier país". En este ámbito, el Convenio europeo para la salvaguarda de los derechos humanos y las libertades fundamentales, de 1950, se ha convertido en el mecanismo de protección por excelencia en el caso de los migrantes y refugiados. A pesar de que el número de derechos y libertades que recoge el Convenio son reducidos, puede afirmarse que el sistema regional de protección de los derechos humanos funciona especialmente gracias a la labor del Tribunal Europeo de Derechos Humanos (TEDH). Los derechos garantizados por el mencionado Convenio se amplían en sus protocolos adicionales ${ }^{33}$.

A nivel regional, el deber de la UE de proteger a las personas que lo necesitan está consagrado en el Tratado de Funcionamiento de la Unión Europea ${ }^{34}$ y en la Carta de los Derechos Fundamentales de la Unión Europea del año $2000^{35}$. La Carta define además derechos aplicables a nivel comunitario, en particular los relativos a la dignidad, libertad, igualdad, ciudadanía y justicia, teniendo ahora el mismo carácter vinculante que los Tratados. En su artículo 18 se garantiza el derecho de asilo $^{36}$. La falta de cumplimiento de estos Tratados es lo que ha supuesto una crisis de valores para la $\mathrm{UE}^{37}$.

Tras finalizar el programa de la Haya (2005-2009), pensado para fortalecer el espacio de libertad, seguridad y justicia, con una significativa importancia en el control de fronteras; el Pacto Europeo de Inmigración y Asilo (2008) estableció una explícita conexión entre inmigración y asilo,

Reedición. Ginebra, diciembre de 2011, UNHCR-ACNUR, pp.7-8. Disponible en: <http://www.refworld.org/cgibin/texis/vtx/rwmain/opendocpdf.pdf?reldoc=y\&docid=50c1a04a2>. (Acceso el 11.06.2016).

${ }^{33}$ BONDIA, D., "El sistema europeu de protecció dels drets humans", en J. BONET y V. M. SÁNCHEZ (dirs), Els drets humans al segle XXI: continuïtat i canvis, Barcelona, Huygens Editorial, 2007, pp. 207-241.

${ }^{34}$ Tratado de Funcionamiento de la Unión Europea. Disponible en: $<$ http://europa.eu/pol/pdf/consolidatedtreaties es.pdf\#page $=57>$.

${ }^{35}$ Carta de los Derechos Fundamentales de la Unión Europea, año 2000. Disponible en: $<\mathrm{ttp} / / /$ www.europarl.europa.eu/charter/pdf/text_es.pdf>.

36 "Artículo 18. Derecho de asilo. Se garantiza el derecho de asilo dentro del respeto de las normas de la Convención de Ginebra de 28 de julio de 1951 y del Protocolo de 31 de enero de 1967 sobre el Estatuto de los Refugiados y de conformidad con el Tratado constitutivo de la Comunidad Europea. Disponible en: < http://www.europarl.europa.eu/charter/pdf/text_es.pdf>.

${ }^{37}$ Las numerosas disposiciones que regulan el asilo constituyen un entramado normativo en constante cambio (puesto que su análisis exhaustivo y, sobre todo, los debates que ha conllevado, supera las posibilidades de este estudio). A modo de ejemplo, destacamos: Otras disposiciones marcan la regulación de esta materia, entre ellas, el Acuerdo Europeo no 31 sobre la exención de visados para los refugiados, aprobado en Estrasburgo el 20 de abril de 1959; el Acuerdo de adhesión del Reino de España al Convenio de aplicación de Schengen (en concreto los artículos 28 a 38); y el Convenio relativo a la determinación del Estado responsable del examen de las solicitudes de asilo presentadas en los Estados miembros de las Comunidades Europeas, aprobado en Dublín el 15 de junio de 1990. 
enfatizando en su compromiso cuarto la construcción de una Europa de asilo; y se inició el actual programa de Estocolmo (2010-2014) para consolidar el SECA. Como recuerda ACNUR, el SECA sitúa a los Estados Miembros en una posición única para responder coherentemente y de manera justa a las necesidades de los hombres, mujeres y niños que buscan protección en la Unión.

Los problemas que dificultan el acceso al derecho de asilo son numerosos. Unos son de carácter técnico-burocrático (la formación de los agentes involucrados en el mismo, la exclusión a priori de determinados sujetos y los lugares de presentación de las solicitudes) y otros se relacionan con las dificultades para identificar a los potenciales demandantes de asilo, diferenciándolos de otros sujetos de derechos y que, por tanto, amparados por otras normas. Conviene que destaquemos algunas de las dificultades:

a) Movimientos mixtos y asilo

Se insiste en la lucha contra la inmigración irregular y se presentan los datos de denegación de entrada, readmisiones, devoluciones y expulsiones, como un logro de la política migratoria sin entrar a cuestionar, por ejemplo, que entre las 23.889 personas afectadas por estas medidas, en 2013 habría potenciales solicitantes de asilo que no pudieron acceder a este derecho ${ }^{38}$. En efecto, la creciente complejidad de los denominados movimientos mixtos, en los cuales se trasladan personas que usan las mismas rutas con diferentes objetivos y medios de transporte o los servicios de los mismos traficantes, supone un importante reto ${ }^{39}$.

Identificar a los refugiados que van en los flujos mixtos irregulares puede ser extremadamente complejo, en especial cuando los mismos individuos no tienen un único motivo para su movilidad. Una vez que se les identifica, los refugiados necesitan, protección contra la devolución y el acceso a soluciones duraderas. La concienciación sobre la multidimensionalidad del fenómeno de la migración, pueden ofrecer nuevas oportunidades para la protección de los refugiados ${ }^{40}$. Sin embargo, a pesar de

\footnotetext{
${ }^{38}$ Ministerio del Interior, Balance 2013. Lucha contra la inmigración irregular, Abril 2014.

${ }^{39}$ SÁNCHEZ LEGIDO, A., “Entre la obsesión por la seguridad y la lucha contra la inmigración irregular: a propósito de la nueva Ley de asilo", Revista Electrónica de Estudios Internacionales, № 18, 2009, 32 pp; GARCíA AÑóN, J., "Discriminación, exclusión social y conflicto en sociedades multiculturales: la identificación por perfil étnico", en J. GARCÍA AÑÓN y M. RUIZ SANZ (eds.), Discriminación racial y étnica, Valencia, Tirant lo Blanch, 2012, pp. 281-316.

${ }^{40}$ Con la finalidad de ayudar a los gobiernos y a otras partes interesadas a incorporar las consideraciones de protección de los refugiados en las políticas migratorias ACNUR comenzó a desarrollar el denominado "Plan de los 10 Puntos". Dicho plan consta de 10 puntos de acción en los que se proponen herramientas prácticas sensibles a la protección y las estrategias que se podrían adoptar como parte de respuestas coherentes y eficaces para los movimientos mixtos. Se concentra en actividades en países de tránsito o de destino, basado en fundamentos de cooperación y responsabilidad compartida entre los Estados y otras partes interesadas. Incorpora tanto actividades tradicionales de protección como propuestas específicas para proteger a los refugiados y a los solicitantes de asilo que viajan como parte de los movimientos mixtos. El plan especialmente recomienda establecer sistemas de entrada que contengan mecanismos para identificar a los recién llegados que tengan necesidades de protección y satisfacer las necesidades de otras categorías de personas involucradas en los movimientos mixtos. La idea fundamental es establecer un compromiso a largo plazo y un desarrollo sostenible orientado hacia la consolidación de la paz, la democratización y la creación de
} 
los esfuerzos en los últimos años, persiste la confusión especialmente entre determinados colectivos a lo hora de identificar potenciales solicitante de asilo. En este sentido, los mecanismos de identificación de solicitantes adquieren una particular relevancia.

b) Acreditación de un temor fundado a la persecución

Hay grandes dificultades en relación a superar los obstáculos básicamente en la acreditación de la existencia de un fundado temor de persecución o la pertenencia a determinado grupo social ${ }^{41}$. En efecto, ACNUR enfatiza la conexión que puede darse entre asilo y trata, y la posibilidad de concebir éste como una forma de protección si bien hay obstáculos difíciles de salvar unidos especialmente a las cuestiones probatorias propias del procedimiento de asilo. Una de las claves en la identificación de los solicitantes de asilo es su consideración casi automática, a priori, como inmigrantes económicos ${ }^{42}$.

c) Menores como potenciales demandantes de asilo

Uno de los colectivos en los que la falta de una correcta identificación es preocupante es el de los menores. ACNUR recuerda algunos aspectos básicos en el caso de menores potenciales solicitantes de asilo, entre ellos: es de vital importancia detectar de inmediato la presencia de posibles menores no acompañados (MENA) entre los extranjeros que llegan al país, poniendo sus casos en conocimiento de las autoridades competentes en protección de menores; las pruebas de determinación de la edad que generalmente se vienen realizando a los menores no acompañados, no son precisas ya que no toman en consideración aspectos raciales, étnicos, nutricionales, medioambientales, psicológicos y culturales, que tienen una influencia directa en el desarrollo y crecimiento del niño. Así, no se realizan ulteriores pruebas complementarias más allá de la oseométrica de muñeca. Se han detectado deficiencias en el trato que reciben estos menores, incluida la ausencia de representación legal independiente en los procedimientos de repatriación, la falta de información sobre el derecho a solicitar asilo, y el uso de métodos obsoletos y poco fiables para la determinación de la edad. Obviar estos factores así como no constatar márgenes de error en estos exámenes, puede acarrear graves consecuencias para el menor; por último, un menor ignora

oportunidades de medios de vida sostenibles como parte de un enfoque integral y de colaboración. Desde su puesta en marcha, España ha realizado diversas actividades que se enmarcan en el catálogo de buenas prácticas, algunas relacionadas con sistemas de ingresos sensibles a la protección. ACNUR, "La protección de los refugiados y la migración mixta: el Plan de los 10 puntos en acción" febrero de 2011. Las referencias a España pueden encontrarse en las pp. 41, 67, 101, 144, 169 y 298. Disponible en:

<http://docplayer.es/11549483-La-proteccion-de-los-refugiados-y-la-migracion-mixta-el-plan-de-los-10puntos-en-accion-comision-europea-ayuda-humanitaria.html>. (Acceso el 15.04.2016).

${ }^{41}$ Defensor del Pueblo, Informe Anual 2013, p. 176.

42 Vid. DE LUCAS, J., "Dos test sobre la consistencia del Estado de Derecho. Ante los proyectos de reforma de asilo y extranjería", Jueces para la democracia, no 64, 2009, pp. 15-23 y "Sobre los fundamentos de la igualdad y del reconocimiento. Un análisis crítico de las condiciones de las políticas europeas de integración ante la inmigración", en AA. VV., Inmigración e integración en la UE. Dos retos para el siglo XXI, Bilbao, Eurobask, 2012, pp. 11-91. 
que su experiencia y las circunstancias vividas en su país de origen podrían ser motivo de la protección internacional y desconoce su derecho a pedir asilo, por tanto, los Servicios Competentes de Protección de Menores son los responsables de proporcionarle la ayuda que necesita ${ }^{43}$.

\section{REFUGIADOS Y SOLICITANTES DE ASILO EN EUROPA: ESTADO ACTUAL DE LA CUESTIÓN}

Europa está viviendo la peor crisis migratoria desde el fin de la Segunda Guerra Mundial. En el verano de 2015, la cifra de inmigrantes y solicitantes de asilo había superado las 350.000 personas. Entre las miles de personas que cruzan el Mediterráneo para llegar a tierras europeas hay dos clases de perfiles con condiciones diferentes, la de los inmigrantes y la de los refugiados. La mayoría de los demandantes de asilo se dirigen a Alemania, aunque eso les suponga pasar meses de penalidades para llegar.

Según el Alto Comisionado de las Naciones Unidas para los Refugiados (ACNUR), en 2013 cerca de 890.000 personas solicitaron asilo en todo el mundo. La mayoría de los refugiados de todo el mundo son acogidos en los países en desarrollo y la mayor parte de los que huyen de su país buscan refugio en los países vecinos. Sin embargo, la Unión Europea en su conjunto recibió en torno a un $43,5 \%$ del total de las solicitudes de asilo tramitadas en todo el mundo.

En caso de que una persona no reúna los requisitos para que se le considere un refugiado, pero no pueda, sin embargo, regresar a su país de origen debido al riesgo real de sufrir daños graves (pena de muerte o ejecución, tortura, trato inhumano o degradante o amenazas graves para la vida o para su persona como consecuencia de violencia indiscriminada), tiene derecho a una protección subsidiaria. Los beneficiarios de la protección internacional gozan de un conjunto mínimo de derechos, como el derecho a la no devolución (que significa que no serán repatriados a un lugar donde corran el riesgo de ser perseguidos), a un permiso de residencia y a viajar dentro y fuera de su país de residencia.

Estas personas deben tener también acceso al empleo, asistencia social, asistencia médica y educación, y a todos los programas que puedan facilitar su integración en el país de residencia ${ }^{44}$. Sin embargo, dependiendo de las normas nacionales, los beneficiarios de la protección subsidiaria

\footnotetext{
${ }^{43}$ ACNUR, Directrices de protección internacional: Solicitudes de asilo de niños bajo los artículos 1 (A)2 y 1(F) de la Convención de 1951 y/o protocolo de 1967 sobre el Estatuto de los Refugiados, 2009 y Menores no acompañados y la protección de asilo. 2009. Disponible en: < http://www.unhcr.org/5730cad27.pdf>. (Acceso el 05.06.2016).

${ }^{44}$ El Fondo de Asilo, Migración e Integración (FAMI) (2014-2020) contribuirá a apoyar y mejorar los esfuerzos de los países de la UE por aplicar el SECA plena y adecuadamente. Los Estados miembros deben asignar al Fondo de Asilo, Migración e Integración el $20 \%$ de los recursos disponibles para alcanzar este objetivo. Una de las principales actividades que deben recibir financiación es la disposición de condiciones de acogida adecuadas para los desplazados y para los solicitantes y beneficiarios de protección internacional. El papel de la Oficina Europea de Apoyo al Asilo (EASO) se ampliará, sobre todo en lo que respecta a la cooperación con los países no pertenecientes a la UE.
} 
pueden recibir un trato menos favorable en determinados casos, como en el acceso a la asistencia social $^{45}$.

La gran mayoría de las personas que han llegado a las costas griegas e italianas a lo largo de 2015 son tanto refugiados como migrantes. Proceden de países afectados por la guerra o que son considerados como países expulsores de refugiados, y por lo tanto requieren protección internacional. Sin embargo, una parte más pequeña de ellos procede de otros lugares y para muchas de estas personas el término 'migrante' sería el más apropiado.

Pueden distinguirse dos tipos de medidas en la política de la UE en relación al asilo entre 2015 y 2016. En una primera fase, se ha procedido a establecer unas cuotas de recepción de refugiados para cada país de la UE; la segunda medida, dado que no ha sido viable, en la práctica, este reparto de cuotas, unido a la resistencia de algunos países a recibirlos, se la firmado un Acuerdo con Turquía. Vamos a analizar brevemente cada una de estas dos fases.

Con un sistema que concentra el $72 \%$ de las demandas de asilo en cuatro países —un tercio del total recae en Alemania-, Bruselas ha decidido actuar por dos vías. De manera inmediata, activó el sistema de emergencia previsto en los tratados cuando se detecte "un influjo repentino" de extranjeros de un país tercero. Ese mecanismo permitirá una distribución de demandantes de asilo "con una participación justa y equilibrada" de todos los Estados miembros. Y con carácter permanente, Bruselas ha presentado una nueva norma que distribuya a los inmigrantes "de manera obligatoria y automática" cuando haya una afluencia masiva de extranjeros. Por tanto, el Ejecutivo de Bruselas, ante la falta de una política común de asilo en la UE, y ante la llegada de más de 160.000 refugiados a Grecia e Italia (hasta septiembre de 2015) decidió establecer unas cuotas para repartir a los inmigrantes que piden asilo. La Comisión ha propuesto que los flujos de extranjeros se repartirán "de manera obligatoria y automática" cuando haya una afluencia masiva. España deberá acoger a 14.931 personas, una cantidad que es la tercera más alta de la UE, detrás de Alemania (31.443 refugiados) y Francia (24.031). El cálculo de Bruselas se basa en cuatro criterios de distribución: la población, el PIB, el nivel de desempleo y el esfuerzo previo de acogida de cada país.

Pese a su fama de insolidaria, Alemania es el país de la UE que más solicitudes de asilo ha acogido (un millón en 2015) (seguido de Suiza) y el que más ayudas proporciona para la integración

\footnotetext{
${ }^{45}$ En el año 2014 solicitaron protección internacional en España 5.947 personas, lo que supone tan solo el 0,95 $\%$ de quienes lo hicieron en el resto de la Unión Europea, según informa la Comisión Española de Ayuda al Refugiado (CEAR). Los sirios fueron con diferencia quienes más solicitaron asilo el año pasado, un total de 1.679 personas, seguidos de los ucranianos (946) y de los malienses (620). Que estas tres nacionalidades sean las que más hayan presentado peticiones tiene su razón en los conflictos armados y el terrorismo que asola a estos países: la guerra civil siria, el conflicto ucraniano y el grupo terrorista Boko Haram que ocupa parte de Malí. El resto de refugiados que más solicitaron protección por nacionalidad fueron los argelinos, los palestinos, nigerianos, pakistaníes, somalíes, venezolanos e iraquíes. De las 5.947 solicitudes de asilo en España en 2014, a 2.029 se les denegó. A quienes se le otorgó la protección internacional, la Comisión Interministerial de Asilo y Refugio aprobó la concesión del estatuto de refugiado a 384 personas, la protección subsidiaria a 1.199 y tan solo a dos personas la residencia por razones humanitarias. En la UE un total de 89.815 personas lograron el estatuto de refugiado. Periódico ABC (02.09.2014). Disponible en: < http://www.abc.es/espana/20150902/abci-diferencias-migrante-refugiado-201509011803.html>.
} 
de los refugiados. A finales de 2015, el Gobierno de Ángela Merkel mostró una actitud abierta y generosa con respecto a los refugiados ${ }^{46}$.

Sin embargo, estos propósitos pronto se cambiaron. El Acuerdo de Dublín, que establece el principio de que se debe de acoger en el país de entrada, no se conseguía llevar a la práctica. Italia y Grecia, estaban desbordados por la afluencia masiva de refugiados que llegaban a sus costas, y no contaban con la estructura ni la organización necesaria para registrar la entrada de un número tan elevado de refugiados. Y, por otro lado, los refugiados se ponían inmediatamente en marcha, atravesando la Unión, poniendo de manifiesto la debilidad de la política fronteriza de la UE. La libre circulación de personas que permite Schenguen no se puede mantener si no se controlan las fronteras exteriores. En esas fronteras exteriores es donde se debían de haber establecido los sistemas de identificación para hacer cumplir la regulación internacional del derecho de asilo. Pero los puntos de identificación se han creado tarde y no han llegado a funcionar.

Las voces contrarias a la recepción de estos refugiados se han dejado oír: desde quienes alegan a que mezclado con los refugiadas van a llegar terroristas islámicos y partidarios del Califato, para propagar su doctrina y para llevar a cabo atentados, a quienes sostienen que Europa no se ha recuperado aún de la crisis económica, con la drástica reducción de derechos sociales que ello ha supuesto y con las consiguientes dificultades de acceso al mercado de trabajo, por lo que no está en condiciones de recibir a miles de personas a las que habría que dar todo tipo de cobertura (educación, sanidad, vivienda) ${ }^{47}$. Las imágenes que reproducen los medios de comunicación (familias

\footnotetext{
${ }^{46}$ Además de proporcionarles techo, manutención, servicios sanitarios y ropa, los refugiados que llegan a Alemania reciben 143 euros mensuales en metálico para sus gastos. Esta situación, que garantiza la Ley de Asilo, se prolonga durante tres meses, tras los cuales se les proporciona aprendizaje de la lengua alemana y formación profesional que les permita integrarse en el mercado laboral. Durante este segundo periodo y hasta que se independizan del Estado germano, pasan a estar bajo protección de otra ley, la conocida como Hartz IV, y reciben mensualmente entre 287 y 359 euros por persona dependiendo de la situación de cada uno, además de 84 euros mensuales por hijo y el coste del alojamiento, medicinas y otros bienes de primera necesidad, incluida la calefacción, hasta que empiecen a trabajar y valerse por sus propios medios. Estos gastos, sumados a los costes extraordinarios de personal para los trámites burocráticos, los programas activos de búsqueda de empleo y los costes de la seguridad de los albergues, debido a que están aumentando los ataques violentos, sumarán una cantidad hasta diciembre de 10.000 millones de euros en un año.

${ }^{47}$ La polémica sobre qué decisión adoptar con respecto a los inmigrantes (no tanto con respecto a los refugiados) ha sido uno de los puntos que han animado a los votantes en el referéndum en Inglaterra, celebrado el 23 de junio de 2016, para pedir que Inglaterra salga de la UE. Brexit es el término que se ha acuñado con el que suele aludirse a una hipotética salida del Reino Unido de la Unión Europea. Es un acrónimo inglés formado por la unión de Britain (Gran Bretaña, y por extensión Reino Unido) y exit (salida). El primer ministro británico, David Cameron, anunció, a principios de 2013, la celebración de esta consulta si ganaba las elecciones generales de 2015. Cameron lo hizo en respuesta a las presiones ejercidas por parlamentarios de su partido y por miembros del UKIP (Partido por la Independencia del Reino Unido), que defendían que los británicos no se han podido pronunciar desde la consulta de 1975 en la que votaron a favor-67\% de los sufragios- de permanecer en el bloque comunitario. A lo largo de estos años, ha ido aumentando el número de británicos que se quejaban de que Inglaterra admitía muchos inmigrantes, de que la libre circulación de trabajadores en el espacio de la UE provocaba alto número de no nacionales ingleses, y de que Inglaterra no podía adoptar sus propias decisiones como Estado soberano, al tener que depender del gobierno de Bruselas. Los euroescépticos y antieuropeos han enarbolado sin complejos la bandera del control de la inmigración y el reforzamiento de las fronteras. En general, el bando proeuropeo habla de economía y el euroescéptico habla de inmigración. Algún ciudadano, cuando se le pregunta al respecto, responde: "Hay demasiada inmigración y no hay sitio para todos [...] Los inmigrantes contribuyen a este país. Pero ahora hay demasiados polacos, rumanos, húngaros. No creo que haya que parar la inmigración, solo controlarla". La pregunta de la papeleta
} 
con menores caminando bajo las inclemencias del invierno por Macedonia y Hungría, policía fronteriza que les impide la entrada en el país) son criticadas por intentar mover a una sensiblería demagógica.

Frente a quienes abren sus puertas a los migrantes, otros comienzan a levantar muros para frenar su avance. Los grandes beneficiados de la última ampliación de Europa (Polonia, Eslovaquia y Hungría ${ }^{48}$ ) se han mostrado reticentes a la política de cuotas. Asimismo, si bien en un principio Austria había abierto su frontera para permitir el paso hacia Alemania de decenas de miles de refugiados durante 2015 y de criticar la decisión de Hungría de construir una alambrada contra los migrantes, el Gobierno austriaco ha dado un giro a su discurso en los últimos meses, en parte en un intento de responder al avance en las encuestas de la ultraderecha, que clama por un cierre total del país. Austria registró el año pasado 90.000 peticiones de asilo. En abril de 2016 ha decidido medidas drásticas para detener nuevos flujos de migrantes y reducir las peticiones de asilo. Tras fijar un límite anual a las solicitudes de acogida y reforzar con una valla su frontera con Eslovenia -el primer paso para el cierre de la llamada ruta de los Balcanes-, el Parlamento ha votado una dura reforma de la ley de asilo que prevé, entre otras cuestiones, la posibilidad de que el Gobierno decrete un estado de "emergencia" que le permita rechazar a posibles refugiados en la frontera. Asimismo, la reforma también pone límites al reagrupamiento familiar y convierte a los perseguidos en refugiados provisionales durante tres años, tras lo cual se revisará la situación en sus países de origen y se prolongará o no su estancia en Austria.

La legislación española está en la línea de la legislación europea en materia de asilo ${ }^{49}$. Hay que destacar que no ha sido un ejemplo de solidaridad. España, según la distribución de cuotas,

del referéndum ha sido: “¿Debe el Reino Unido permanecer como miembro de la Unión Europea o debe abandonar la Unión Europea?”. "Referédum sobre el Brexit”. Diario El País, 24.06.2016. Disponible en. http://internacional.elpais.com/internacional/2016/06/15/actualidad/1465985703_933248.html. (Acceso el 23.06.2016).

Los votantes han tenido que elegir entre permanecer o abandonar. Los británicos, por un 51,9\% contra un 48,1\% de los votos, habían decidido abandonar la Unión Europea., finalmente, los británicos, por un 51,9\% contra un $48,1 \%$ de los votos, han decidido abandonar la Unión Europea. Este referéndum ha sido histórico porque en gran medida determinaba el futuro no solo de Reino Unido, también de la Unión Europea y su proyecto, en construcción desde hace más de 50 años. El hecho de que haya ganado que Reino Unido debe de salir de la UE ha sentado un precedente para que otros países también quieran salir (Escocia ya ha solicitado que se lleve a cabo un referéndum para decidir su independencia). El Partido laborista no ha tenido -o no ha sabido dar- argumentos para responder al miedo a la inmigración entre las clases trabajadoras, que el referéndum ha revelado como uno de los conflictos sociales más importantes del país. "Referéndum de permanencia en la UE Reino Unido vota por dejar la Unión Europea”. Diario El País, 24.06.2016. Disponible en: http://internacional.elpais.com/internacional/2016/06/24/actualidad/1466741749_403437.html?rel=cx_articu lo\#cxrecs_s. (Acceso el 24.06.2016).

${ }^{48}$ Los refugiados, a lo largo de 2015, se agolpaban en las fronteras de países como Hungría, que no les dejaba avanzar hacia Alemania, ya que selló la frontera y criminalizó la entrada ilegal de emigrantes. El primer ministro húngaro, Viktor Orban, ha anunciado un referéndum sobre las cuotas de refugiados, porque "Podrían redibujar la identidad religiosa y cultural de Europa".

${ }^{49}$ Vid. Ley 12/2009, de 30 de octubre, reguladora del derecho de asilo y de la protección subsidiaria. Disponible en: <https://www.boe.es/buscar/act.php?id=BOE-A-2009-17242>. (Acceso el 09.06.2016). El Título I se dedica a los requisitos que deben cumplirse para dar lugar a la concesión del derecho de asilo derivado del reconocimiento de la condición de persona refugiada o beneficiaria de protección subsidiaria. Se detallan y delimitan, también por vez primera, todos los elementos que integran la clásica definición de refugiado: persecución, motivo de persecución y agente perseguidor. Es en este Título en el que encuentran cabida 
debía de recibir a 15.000 refugiados en 2015; hasta ahora (junio de 2016) ha recibido 120 refugiados. Por otro lado, algunas de las pocas personas que han llegado se encuentran con condiciones de hacinamiento en los centros de Estancia temporal para Inmigrantes (CETI) y no suelen disponer de una información clara para solicitar asilo. Precisamente, en la reivindicación del asilo como un derecho, España tiene un reto como es el de la especial situación en Ceuta y Melilla ${ }^{50}$ como punto de presentación de solicitudes de asilo. Los solicitantes de asilo en Ceuta y Melilla son conducidos a los CETI, en los que coinciden tanto inmigrantes como solicitantes de protección internacional, que se ven impedidos para ejercer la libre circulación dentro del territorio nacional con el consiguiente agravio comparativo en relación con los CAR que se encuentran en la Península. El Comité DESC ha expresado su preocupación por la reducción de los niveles de protección efectiva de los derechos consagrados en el Pacto que ha resultado de las medidas de austeridad adoptadas por el Estado español, perjudicando de forma desproporcionada al disfrute de sus derechos por las personas y los grupos desfavorecidos y marginados, entre ellos los solicitantes de asilo ${ }^{51}$.

\title{
5. EL ACUERDO UE-TURQUÍA FRENTE A LAS GARANTÍAS EN MATERIA DE ASILO
}

\begin{abstract}
algunos de los aspectos más innovadores de la Ley, con especiales referencias a la dimensión de género en relación con los motivos que, en caso de existir persecución, pueden conducir a la concesión del estatuto de refugiado. Se incluyen igualmente, y con un detalle sin precedentes en nuestra legislación, las correlativas causas que determinan el cese o la exclusión del disfrute del derecho de asilo. El Título $\mathrm{V}$ se dedica a los menores y a otras personas vulnerables necesitadas de cualquiera de las dos modalidades de protección internacional que regula la Ley. La inclusión de este Título y el tratamiento que en él se otorga a las personas a que se refiere constituyen otra novedad, que viene a subsanar la falta de referencias explícitas a ellas, en especial a los menores, y más en concreto a los no acompañados, en nuestra legislación de asilo. Con ello, se profundiza en la mencionada línea garantista derivada del interés superior del menor y de la voluntad de evitar discriminaciones por razón de género o que afecten a personas con discapacidad, personas mayores y otras en situación de precariedad, pues alcanza a todos los ámbitos del sistema de asilo. Vid. SOLANES, A., "Asilo: un derecho en cuestión. Análisis desde la realidad española a la luz de las disposiciones europeas" en Revista Acadêmica, vol.85, no2, 2013, pp.50-97. Disponible en: < www.repositorios.ufpe.br/revistas/index.php/ACADEMICA/article/download/.../426>. (Acceso el 05.06.2016). ${ }^{50}$ Entre 2007 y 2013, Europa gastó 4.000 millones de euros en inmigración y refugio, de los cuales, sólo un 17\% se empleó en atención al asilo. En el caso de España, también hay un claro contraste entre el presupuesto empleado en proteger las fronteras en lugar de a las personas: 290.000 millones destinados a las fronteras y 9.000 millones de euros destinados a la atención de personas refugiadas. La instalación y mantenimiento de vallas en Ceuta y Melilla se ha llevado una buena parte de ese presupuesto. (FIBLA, C., "Huyen del horror y acaban en el infierno" en El Notario del siglo XXI, Revista del Colegio Notarial de Madrid, no67, mayo-junio 2016, p.35).

${ }^{51}$ Por ello, el Consejo DESC recomienda al Estado "que garantice que todas las medidas de austeridad adoptadas identifiquen el contenido mínimo esencial de todos los derechos del Pacto, y que tome todas las medidas apropiadas para proteger este contenido esencial en cualquier circunstancia, especialmente para las personas y los grupos desfavorecidos y marginados. En este contexto, el Comité recomienda al Estado parte que recopile información estadística desagregada, con el objeto de identificar a las personas y grupos afectados y aumentar la eficacia de sus esfuerzos para la protección de sus derechos económicos, sociales y culturales. El Comité también señala a la atención del Estado parte su carta abierta sobre los derechos económicos, sociales y culturales en el contexto de la crisis económica y financiera, con fecha 16 de mayo de 2012", Consejo Económico y Social, Observaciones finales del Comité DESC. España. 2012, op. cit., pár. 11, p. 7. Sobre la directa relación entre estos derechos y la integración de los extranjeros vid. AÑÓN ROIG, Mã.., "Integración: una cuestión de derechos", Revista Arbor, n.o 477, 2010, pp.625-638.
\end{abstract}


Para resolver las tensiones y desacuerdos que había supuesto la política de cuotas de refugiados, se concretó una segunda medida, por la que Europa y Turquía han pactado un cambio radical en la gestión la crisis de los refugiados, ante las enormes dificultades para conseguir distribuirlos mediante cuotas. La desesperación por frenar el flujo migratorio ha llevado a los Veintiocho a forjar un polémico acuerdo con Turquía para devolver a ese país a todo extranjero que llegue ilegalmente a las costas griegas, incluso a los sirios. A cambio, la UE se compromete a traer desde Turquía a un número de refugiados equivalente al de expulsiones. El Acuerdo que cerraron en Bruselas los jefes de Estado y de Gobierno, incluye otras tres condiciones para Europa: aumentar los 3.000 millones destinados a Turquía para atender a los refugiados, eximir a sus ciudadanos de la necesidad de visado para viajar a la UE ya en junio de 2016 y avanzar en el proceso de adhesión al club comunitario.

La ley internacional, con la Convención de Ginebra, estipula que quien llega a un territorio puede pedir asilo, y no puede ser expulsado o deportado hasta que se resuelva su expediente. Pero la Directiva europea, según su artículo 33, permite a un país rechazar una petición de asilo si la persona viene de un país seguro. Y esto es lo que se ha utilizado en la UE ya que como Turquía es un "país seguro" y allí no hay guerra, técnicamente podrían ser devueltos aprovechando los acuerdos bilaterales entre países, incluyendo Grecia y Turquía. Además, para desincentivar los desplazamientos hacia Grecia, puerta de entrada en Europa desde Siria, se ha acordado que serán deportados y pasarán al final de la lista para ser recolocados", Ahí está la esencia: los que decidan gastarse miles de euros para cruzar el mar arriesgando su vida serán además 'castigados', siendo relegados a la lista por la que se reubicará directamente en Estados de la Unión a los demandantes.

Básicamente, el citado Acuerdo establece:

- "retornar a todos los nuevos migrantes irregulares que pasen de Turquía a las islas griegas, haciéndose la UE cargo de los costes;

- reasentar, por cada sirio readmitido por Turquía desde las islas griegas, a otro sirio desde Turquía en los Estados miembros de la UE, en el marco de los compromisos vigentes;

- acelerar la ejecución de la hoja de ruta para la liberalización de los visados con todos los Estados miembros con vistas a la eliminación de la exigencia de visado para los ciudadanos turcos a más tardar a finales de junio de 2016;

- agilizar el desembolso de los 3000 millones de euros inicialmente asignados para garantizar la financiación de un primer conjunto de proyectos antes de finales de marzo y decidir sobre una financiación adicional para el Mecanismo para los refugiados en favor de los sirios;

- preparar lo antes posible la decisión relativa a la apertura de nuevos capítulos en las negociaciones de adhesión, basándose en las Conclusiones del Consejo Europeo de octubre de 2015;

- trabajar con Turquía en cualquier empeño común para mejorar las condiciones humanitarias en el interior de Siria que permita a la población local y a los refugiados vivir en zonas más seguras". 
Y trabajarán sobre las siguientes bases: ${ }^{52}$

a) "proporcionar más ayuda a Grecia en la gestión de las fronteras exteriores, también con la Antigua República Yugoslava de Macedonia y Albania, y garantizar el correcto funcionamiento de los puntos críticos, con un $100 \%$ de identificación, registro y controles de seguridad, y la existencia de medios de acogida suficientes. Frontex organizará una nueva convocatoria para agentes invitados nacionales tan pronto como sea posible, y todos los Estados miembros deberían responder plenamente a más tardar el 1 de abril. Europol enviará rápidamente agentes invitados a todos los puntos críticos para reforzar los controles de seguridad y ayudar a las autoridades griegas a luchar contra los traficantes;

b) ayudar a Grecia para garantizar un retorno exhaustivo, de gran magnitud y por la vía acelerada a Turquía de todos los migrantes irregulares que no estén necesitados de protección internacional, sobre la base del acuerdo de readmisión celebrado entre Grecia y Turquía y, desde el 1 de junio, del acuerdo de readmisión entre la UE y Turquía;

c) agilizar sustancialmente la puesta en práctica de la reubicación con el fin de aliviar la pesada carga que soporta Grecia en estos momentos. La Oficina Europea de Apoyo al Asilo volverá a solicitar asesoramiento nacional para apoyar el sistema de asilo griego y todos los Estados miembros deberían responder rápida y plenamente. Se invita asimismo a los Estados miembros a que ofrezcan más espacios de reubicación con carácter urgente. La Comisión informará mensualmente al Consejo acerca de la ejecución de los compromisos de reubicación;

d) seguir cooperando estrechamente con los países de los Balcanes Occidentales que no son miembros de la UE y prestarles toda la ayuda necesaria;

e) ejecutar los actuales compromisos de reasentamiento y seguir trabajando en un programa creíble y voluntario de admisión humanitaria con Turquía;

f) tomar de inmediato todas las medidas necesarias respecto de cualquier nueva ruta que pueda abrirse e intensificar la lucha contra los traficantes;

52 Documento disponible en: http://www.consilium.europa.eu/es/press/press-releases/2016/03/07-euturkey-meeting-statement/. 
g) impulsar, con carácter prioritario, todos los elementos de la hoja de ruta de la Comisión para «Restablecer Schengen», de modo que se ponga fin a los controles temporales en las fronteras interiores y restablezca el normal funcionamiento del espacio Schengen antes de finales de año.

El presente documento no establece ningún nuevo compromiso para los Estados miembros por lo que a reubicación y reasentamiento se refiere".

La valoración de este Acuerdo ha sido variada, desde quienes consideran que es un importante paso para superar la crisis de los refugiados a quienes lo califican negativamente, como "casi tráfico de personas", subrayando que la Unión Europea culmina su ataque contra las personas refugiadas a través de un acuerdo de expulsión masiva a Turquía $^{53}$. Para los críticos de este Acuerdo, el 19 de marzo de 2016, Europa ha firmado con Turquía el mayor acuerdo antirrefugiados de las últimas décadas, un acuerdo que no sólo viola los "valores europeos" y la Carta de Derechos Fundamentales, sino también la Convención Europea de Derechos Humanos, la Declaración Universal de Derechos Humanos, la Convención de Ginebra sobre los Refugiados y la Convención sobre los Derechos del Niño. El acuerdo se enmarca en una especie de "Europa fortaleza".

El Acuerdo, señala explícitamente que cualquier modalidad de implementación del acuerdo respetará la legislación internacional y europea. Según la interpretación de $\operatorname{ACNUR}^{54}$, a la luz de la jurisprudencia pertinente, esto significa que las personas en necesidad de protección internacional serán entrevistadas de forma individual para determinar si sus solicitudes pueden ser estudiadas en Grecia, y tendrán derecho a interponer un recurso antes de que tenga lugar cualquier readmisión a Turquía. Esto también supondría que una vez retornadas, las personas que necesitan protección internacional tendrán la oportunidad de solicitar y tener acceso de forma efectiva a protección en Turquía. Ahora tenemos que ver cómo funcionará en la práctica, manteniendo las garantías establecidas en el acuerdo, muchas de las cuales en la actualidad no están operativas. La forma en que este plan sea puesto en marcha será, por tanto, crucial. En última instancia, la respuesta debe centrarse en abordar las necesidades apremiantes de las personas que huyen de la guerra y la persecución. Los refugiados necesitan protección, no rechazo.

En primer lugar, se deben reforzar con celeridad las condiciones de recepción en Grecia y sus sistemas para estudiar las solicitudes de asilo y para atender a las personas que sean aceptadas como refugiadas. Las garantías en el acuerdo tienen que ser establecidas e implementadas. Esto supondrá un enorme reto que tiene que ser abordado de manera urgente.

En segundo lugar, las personas retornadas a Turquía y en necesidad de protección internacional deben tener acceso a un procedimiento justo y adecuado de determinación de su solicitud, y en un plazo razonable. Deben existir garantías frente al refoulement (devolución de una persona a un lugar donde su libertad, su vida o su integridad física pudieran correr peligro) o el

\footnotetext{
${ }^{53}$ Disponible en: <http://iniciativadebate.org/2016/04/01/acuerdo-ue-turquia-casi-trafico-personas/> (Acceso el 04-04.2016).

${ }^{54}$ Posición de ACNUR sobre el acuerdo UE-Turquía: deben prevalecer las garantías en materia de asilo. Disponible en: http://www.acnur.org/t3/noticias/noticia/posicion-de-acnur-sobre-el-acuerdo-ue-turquiadeben-prevalecer-las-garantias-en-materia-de-asilo/.
} 
retorno forzado. Asimismo, en Turquía deben haberse establecido la capacidad de recepción y otros aspectos antes de que cualquier persona sea retornada desde Grecia. Las personas que sean reconocidas en necesidad de protección internacional tienen que poder disfrutar del asilo, sin discriminación y de acuerdo con los estándares internacionales aceptados, incluyendo el acceso efectivo al trabajo, salud, educación para los niños y, en la medida en que lo necesiten, asistencia social.

En tercer lugar, si bien ACNUR toma nota del compromiso que establece este acuerdo para incrementar las oportunidades de reasentamiento para refugiados sirios desde Turquía, es crucial que estos compromisos sean significativos y predecibles. El incremento del reasentamiento desde Turquía a la Unión Europea no puede ser a expensas del reasentamiento de otras poblaciones de refugiados en todo el mundo que también tienen grandes necesidades, especialmente en el contexto actual en el que se registran las mayores cifras de desplazamiento a nivel mundial.

\section{LA GLOBALIZACIÓN DE LA INDIFERENCIA}

No es fácil el análisis de la situación de los desplazados. No basta con un humanismo simplón ni con un mero recurso abstracto a la teoría de los derechos humanos. Por un lado, esta situación ha dado lugar a una creciente ola de racismo y xenofobia, a un trasvase de votos a la ultraderecha, que defienden la idea de "Europa fortaleza". Por otro lado, están los partidos políticos populistas y algunas ONG y Organizaciones que denuncian la falta de solidaridad que supone denegar asilo a los refugiados ${ }^{55}$.

El derecho de asilo merece una reflexión sobre la fundamentación filosófica del mismo ${ }^{56}$. Como señala De Lucas, "Ios fundamentos del derecho de asilo hay que buscarlos en las nociones de humanidad -humanitas- dignidad humana y solidaridad o, más aún, en la universalidad de los derechos humanos" ${ }^{57}$. El derecho de asilo representa, en su punto superior, la escala del proceso de generalización de los derechos humanos (para todos) y en la inferior, la especificación de los derechos humanos. La humanitas consiste en afirmar la irreductiblidad del hombre al ciudadano, la consistencia de la dignidad radical del hombre como algo previo a su pertenencia a cualquier grupo.

También surge aquí el término clásico, la idea del "extranjero", del "otro", como símbolo que ha formado parte de la historia del pensamiento occidental. El refugiado viene a representar al

\footnotetext{
${ }^{55}$ Los medios de comunicación también han jugado su papel, especialmente con el tema de los desplazados procedentes de Siria. Han dejado en nuestra retina la imagen del niño sirio Aylán, muerto en una playa de Lesbos en septiembre de 2015, que había perecido ahogado en una playa, intentando llegar a nuestras costas con su familia (<http://www.elperiodico.com/es/noticias/internacional/imagen-aylan-nino-sin-vida-una-playaturca-vuelve-inmediato-simbolo-4476423> (Acceso el 14.06.2016); la periodista que puso la zancadilla a un hombre que corría con su hijo en brazos, intentado escapar de la policía que les iba a devolver a la frontera -la periodista fue despedida del periódico para el que trabajaba-. Son escenas llamadas a conmover la sensibilidad de quien asiste cómodamente al visionado de las mismas desde el sillón de su casa.

${ }^{56}$ DE LUCAS, J., "Fundamentos filosóficos del derecho de asilo" en Derechos y Libertades, Universidad Carlos III de Madrid. Instituto Bartolomé de las Casas- BOE, enero-junio 1995, pp.23-56. http://earchivo.uc3m.es/handle/10016/1234\#preview.

${ }^{57}$ DE LUCAS, J., "Fundamentos filosóficos del derecho de asilo", cit., p. 26.
} 
extraño. Pone a prueba los principios de dignidad y solidaridad para ver si son algo más que mera retórica.

La solidaridad puede considerarse como principio, valor, norma y derecho constitucional e incardina un poder jurídico que establece límites al poder mismo y a otros derechos dependiendo el caso concreto. En cumplimiento del principio de solidaridad, es obligación del Estado destinar parte de los recursos, y ser puesto al servicio de los más necesitados conforme a los programas de solidaridad, a fin de evitar el deterioro de la persona humana. Como acertadamente advierte Fernández Segado ${ }^{58}$, en el plano de la ética la solidaridad aparece como una virtud moral; puede afirmarse que nos hallamos ante un auténtico valor ético-moral que bien podría compendiarse en la idea de fraternidad. Ser solidario, en pocas palabras, es asumir como propio el interés de un tercero, identificarse con él. En el plano social, la solidaridad constituye un ingrediente esencial, la verdadera conditio sine qua non de la existencia de un grupo social, pues, como con toda razón se ha apuntado, sin solidaridad no hay muchas posibilidades de que exista un grupo humano digno de tal nombre.

La solidaridad, conjuntamente con la libertad, la igualdad y la justicia, han venido a conformar lo que podría tildarse de tetralogía axiológica del Estado social de nuestro tiempo. Ciertamente, la solidaridad ha sido una noción de menor relevancia dogmática que, por ejemplo, las de libertad e igualdad $^{59}$, pero lo cierto es que, con el devenir del tiempo, la solidaridad, piedra angular de la herencia cultural del humanismo cristiano, se ha convertido en un valor de referencia meta-ideológico, o lo que es igual, en una referencia axiológica general reivindicada desde cualquier posición ideológica ${ }^{60}$.

El derecho de asilo también cuestiona el estatuto de ciudadanía (a su configuración y extensión en cuanto a los efectos de la titularidad de los derechos), a la relación entre democracia y pluralismo cultural y a la noción de igualdad jurídica.

La mundialización, el multiculturalismo y la globalización han sido el caldo de cultivo para que el concepto de ciudadanía se vea inmerso en numerosas polémicas. Siempre ha sido un concepto controvertido pero hoy en día adquiere tintes de mayor complejidad. El significado moderno de ciudadanía ${ }^{61}$ ha estado vinculado a la aparición del Estado-nación y, de ahí que durante largo tiempo se haya equiparado con la posesión de una determinada nacionalidad. Sin embargo, la aparición de realidades emergentes como la de "ciudadano", "extranjero" e "inmigrante" nos obliga a clarificar

\footnotetext{
${ }^{58}$ FERNÁNDEZ SEGADO, F., "la solidaridad como principio constitucional” en UNED. Teoría y Realidad Constitucional, núm. 30, 2012, pp. 139-181. Disponible en: <dialnet.unirioja.es/descarga/articulo/4097796.pdf> (Consultado el 14.08.2015).

${ }^{59}$ GONZÁLEZ AMUCHASTEGUI, J: «Notas para la elaboración de un concepto de solidaridad como principio político», en Sistema. Revista de Ciencias Sociales, no 101, Marzo 1991, págs. 123 y ss.; en concreto, p. 125.

${ }^{60}$ JIMÉNEZ REDONDO, J.C: El valor de la solidaridad en un mundo global, CEU Ediciones, Madrid, 2010, pp. 1112.

${ }^{61}$ Sobre ciudadanía, vid. BELLOSO MARTín, Nuria. Os novos desafíos da cidadanía. Coleçâo Direito e Sociedade Contemporánea. Trad. al portugués de C. Gorczevski. Servicio de Publicaciones de la Universidade de Santa Cruz do Sul -EDUNISC- (Brasil), 2005; también, GORCZEVSKI, C; BELLOSO MARTíN, N., A necessária revisao do conceito de cidadania: movimentos sociais e novos protagonistas na esfera pública democrática. Porto Alegre: EDUNISC, 2011. Disponible en: <http://www.unisc.br/portal/pt/editora/e-books.html>.
} 
algunos conceptos $^{62}$. Y de nuevo nos remontamos al concepto originario de ciudadano pues no puede haber ciudadanía sin determinar quién está incluido y quién queda excluido de ese ámbito. El "otro", el "extranjero", el "inmigrante", es el que queda fuera del manto protector de la ciudadanía que, en principio, nos viene dado por la nacionalidad, pues el "inmigrante" y el "extranjero" son los "nonacionales"63.

En la visita que el Papa Francisco ha realizado, en el mes de abril de 2016, a la isla de Lesbos, en Grecia ${ }^{64}$, puerta de entrada de miles de refugiados sirios, permitía recordar que "Europa es la patria de los derechos humanos", como advirtió Bergoglio, "y cualquiera que ponga pie en suelo europeo debería poder experimentarlo". Hizo un "vehemente llamamiento a la responsabilidad y la solidaridad" internacional. "La preocupación de las instituciones y de la gente", admitió, "es comprensible y legítima, pero no debemos olvidar que los emigrantes, antes que números son personas, son rostros, nombres, historias. Por desgracia, algunos, entre ellos muchos niños, no han conseguido ni siquiera llegar: han perdido la vida en el mar, víctimas de un viaje inhumano y sometidos a las vejaciones de verdugos infames". El Papa pronunció estas palabras en el puerto desde el que son deportados los migrantes. Bergoglio ha calificado esta situación como la catástrofe humanitaria más grande desde la II Guerra Mundial ${ }^{65}$. Incluso el mar, se ha convertido en un gran cementerio donde perecen ahogados muchos de quienes intentar llegar a las costas del sur de

\footnotetext{
${ }^{62}$ Hay diversas propuestas de modelos de ciudadanía cosmopolita, entre los que cabe destacar: 1 . Modelo de patriotismo constitucional de Jürgen Habermas; 2. Modelo de ciudadanía universal de Luigi Ferrajoli; 3. Modelo de ciudadanía constitucional mundial de Peter Häberle; 4 . Modelo de ciudadanía cosmopolita de David Held; 5. Modelo de ciudadanía cosmopolita de Martha Nussbaum.

${ }^{63}$ Vid. MARTínEZ DE PISÓN, J., “Ciudadanía e inmigración”. En: Ciudadanía. Dinámicas de pertenencia y exclusión. (Coordinadores: Mạ.J. Bernuz Beneítez y R. Susín Betrán). Servicio de Publicaciones de la Universidad de La Rioja, 2003, p.79.

${ }^{64}$ El Papa fue recibido en Lesbos por el Presidente de Grecia, Tsipras, el patriarca ortodoxo Bartolomeo y el arzobispo de Atenas, quienes lo acompañarán durante su visita, de apenas cuatro horas, al centro de detención de Moria, donde unos 3.000 migrantes aguardan su expulsión, y al puerto de Mitilene, desde donde parten los baros en que se expulsa a los refugiados.

${ }^{65}$ El papa Francisco no ha dejado de clamar contra la "globalización de la indiferencia" que sufren quienes, ya sea por la guerra o el hambre, tienen que dejar sus países y buscar refugio o trabajo al otro lado del mar y las alambradas. Durante sus tres años como obispo de Roma, han sido muchas las ocasiones en las que Bergoglio se ha referido al drama de la emigración. Y, ya desde el principio, lo hizo exigiendo compromisos concretos, y no solo a los gobernantes. En septiembre de 2013, durante una visita a la sede en Roma de una organización de los jesuitas que presta ayuda a los refugiados, pidió que la Iglesia se involucrara más con el problema utilizando los conventos vacíos como centros de acogida: "Queridísimos religiosos y religiosas: los conventos vacíos no sirven a la Iglesia para transformarlos en hoteles y ganar dinero. Los conventos vacíos no son nuestros, son para la carne de Cristo que son los refugiados". Justo dos años después, y ante la sordera de la comunidad eclesiástica, volvió a la carga. Pidió a las "parroquias, comunidades y religiosas y monasterios" de Europa que abrieran sus puertas a las familias de migrantes. Aquel llamamiento tan concreto-cada comunidad religiosa debería acoger al menos a una familia-- también cayó en saco roto. Como el largo y profundo discurso que, con motivo de la recepción anual al cuerpo diplomático acreditado en el Vaticano, pronunció el pasado 11 de enero. "Europa- dijo el Papa- tiene que vencer el miedo" ante un fenómeno tan imponente porque tiene los instrumentos necesarios para encontrar un justo equilibrio entre el deber moral de tutelar los derechos de sus ciudadanos y el de garantizar la acogida a los emigrantes". Bergoglio recordó a los diplomáticos que no se trata de un problema nuevo: "Toda la Biblia nos narra la historia de una humanidad en camino (...) Es la voz de los que escapan de la miseria extrema (...) Todos saben que el hambre sigue siendo, desgraciadamente, una de las plagas más graves de nuestro mundo, con millones de niños que mueren cada año por esa causa". Decenas de discursos que se han estrellado una y otra vez contra aquella globalización de la indiferencia.
} 
Europa en barcos frágiles, después de haber dado todas sus pertenecías a mafias que trafican con seres humanos.

\section{A MODO DE CONCLUSIONES}

La Unión Europea es probablemente el ámbito donde los derechos humanos gozan de una mejor protección. Sin embargo, el derecho de asilo, institución clásica del Derecho internacional humanitario, se ha visto afectado por la creciente crisis del principio de solidaridad. Como ha escrito Stéfano Rodotà, "hoy el campo de batalla es la ciudadanía. ¿A quién incluir, a quién excluir? ¿con base en qué criterios?". Cabe preguntarse qué mínimo se debe de garantizar a todo ciudadano para que un sistema pueda considerase democrático. $Y$ estos interrogantes resultan oportunos porque uno de los primeras cuestiones que surgen es qué diferencia hay entre aquél que emigra motivado por razones de supervivencia, porque no tienes medios económicos en su país o porque se ha producido una catástrofe natural, y aquél otro que se desplaza por razones de guerra o persecución. ${ }^{66}$

Hasta ahora, nos encontramos en un escenario regional europeo que, además de mostrar una cierta inercia ante la violación sistemática de los derechos humanos en el control intraestatal de las fronteras Schengen, evidencia la descoordinación práctica del sistema común de asilo o la ausencia de garantías jurídicas en los procedimientos de expulsión de nacionales de terceros Estados y minorías étnicas. El Consejo de Europa ya había destacado como principales retos de futuro, aunando la figura de los migrantes y los solicitantes de asilo: la detención injustificada, excesiva o inadecuada; y la falta de una protección básica a los que no son detenidos. Por ello recomienda codificar las normas de detención y ofrecer garantías legales, administrativas y prácticas que permitan a las personas en situación irregular ejercer derechos básicos sin correr el riesgo de expulsión y proteger a los que prestan ayuda humanitaria de los riesgos de las sanciones penales. En definitiva, la reivindicación del asilo como derecho, elemental y primario (por supuesto, humano), exige la no "utilización de las fronteras como violencia", que estigmatiza a los más débiles, lo que conlleva la destrucción del Estado de Derecho.

Se ha intentado dar respuesta a estas cuestiones mediante el nuevo marco jurídico que se ha adoptado en la UE, estableciendo normas comunes detalladas que introducen criterios claros a la hora de determinar las solicitudes de asilo, los procedimientos más eficaces y las mejores condiciones de acogida de los solicitantes. Se han introducido también garantías específicas para determinadas categorías de personas vulnerables, en particular los menores y las víctimas de torturas y violencia, y se reconoce expresamente que los estados miembros deben evitar la detención de los

\footnotetext{
${ }^{66}$ Esta cuestión la planteamos en cuanto a que desde el enfoque de los derechos humanos, no debería haber diferencias. Sin embargo, de facto sí hay diferencias notables, al menos desde una perspectiva práctica. "A diferencia de los inmigrantes, los refugiados no eligen ni el país ni el momento de su huida. Por tanto, la obtención de un visado no se hará en función de la elección del país, sino de la facilidad de obtenerlo, del acceso a un consulado, sin llamar la atención en el país de origen. Si para un perseguido detenerse a obtener un visado ya resulta peligroso o inoportuno, lo es más si accede a determinadas embajadas. Para el refugiado, el visado no es un instrumento de entrada a un país, sino una cierta garantía de no devolución." LLUNCH, T., “Hacia una política común de asilo para la Unión Europea. Afers Internacionals, núm. 53, Fundació CIDOB, 2001, pp. 141-146. Disponible en: <http://www.raco.cat/index.php/revistacidob/article/viewFile/28222/28056>. (Acceso el 14.06.2016).
} 
solicitantes de asilo. El sistema europeo común de asilo (SECA) fue teóricamente pensado con la finalidad de asegurar el asilo como un derecho, articulando un estatuto uniforme de protección. Pero no sólo no se ha completado sino que además, la política de la Unión Europea y los acuerdos adoptados al respecto, como el UE-Turquía, de 18 de marzo de 2016, conllevan una limitación -sino vulneración- del estatuto de refugiado y sacan a la luz las sistemáticas violaciones de derechos humanos que se producen en los movimientos mixtos en España. También hay voces que tratan de reivindicar que las garantías frente a la persecución no pueden ser limitadas, ni los solicitantes de asilo pueden concebirse como un "numerus clausus", porque cuando hablamos de asilo apelamos a un derecho humano conectado con la más elemental protección del género humano ${ }^{67}$.

Todas estas medidas pueden estar orientadas por el refuerzo de los procesos que permitan la construcción de una auténtica sociedad internacional (la institucionalización de la sociedad abierta sustentada por Bergson y por Popper) que haga posible la consecución de la meta propuesta por Kant de un Derecho cosmopolita, al que correspondería la utopía de una ciudadanía en sentido cosmopolita. Constituye un auténtico reto configurar un modelo de Estado que supera los límites del Estado-nación.

Parece que una sociedad abierta, una ciudadanía cosmopolita, es una utopía en la realidad de los Estados nacionales actuales que, aunque a nivel regional participen de unos organismos supranacionales con unos valores e ideario de reconocimiento y garantía de los derechos humanos, tropiezan con la dura realidad de presupuestos limitados y peligros potenciales que pueden traer los refugiados (amenaza de atentados terroristas -mezclándose, entre los refugiados, yihadistas-, incremento del grado de violencia ${ }^{68}$ y otros). En diferentes Estados de la Unión Europea han surgido conflictos en torno al alcance general de los derechos de los extranjeros y al desafío que supone el acceso equitativo tanto al espacio público como a la distribución de poder y de recursos. Esta situación se ha visto acrecentada por el reflejo de la crisis económica que desde 2008 golpea a los países de la UE, lo que ha llevado a mirar al migrante, al extranjero, con desconfianza con respecto a qué parte de las políticas públicas se le iban a destinar a costa de reducirlas para los ciudadanos nacionales. Los principios de libertad y, sobre todo la igualdad, necesitan un replanteamiento.

Todo ello viene a poner de manifiesto la necesidad de una revisión jurídico-política sobre los avances y retrocesos de las políticas migratorias y de asilo, desde una reflexión crítico-constructiva sobre la necesidad de articular políticas y estrategias normativas coherentes con los principios vertebradores del Estado de Derecho y del sistema internacional de protección de los derechos

\footnotetext{
${ }^{67}$ SOLANES CORELLA, Ma A., "Derechos humanos y asilo: sobre las deficiencias del SECA y la regulación jurídica española" en Anuario de la Facultad de Derecho - Universidad de Alcalá VII (2014) 181-210; SOLANES CORELLA, Ma A. (Editora), Diversidad cultural y conflictos en la Unión Europea. Implicaciones jurídico-políticas, Valencia, Tirant lo Blanch, 2016.

68 "Durante la pasada Nochevieja, varias decenas de mujeres sufrieron agresiones sexuales, robos e intimidaciones por parte de una multitud de hombres apostados en los alrededores de la estación central de Colonia, al lado de la famosísima catedral de la cuarta mayor ciudad de Alemania. La policía anunció el lunes que en torno a un millar de hombres - que por su apariencia procedían "de los países árabes o del norte de África" - se congregaron en el lugar de los hechos, que adquirieron "una dimensión desconocida". Diario El País, 06.01.2016. Disponible en: http://internacional.elpais.com/internacional/2016/01/05/actualidad/1451991976_936738.html. (Acceso el 10.06.2016).
} 
humanos. Una vez más, se tiene la sensación de que el Derecho Internacional de los derechos humanos y las políticas de inmigración y asilo en la UE está bien articuladas hasta que llega el momento de llevarlas a la práctica. Es entonces cuando se pone de manifiesto que el sistema internacional de derechos humanos no consigue dar la respuesta que cabría esperar en orden a un reconocimiento real y efectivo de los derechos humanos, que ha sido una de las claves sobre las que se ha construido la UE.

Desde hace años se lleva reclamando a la UE una política común de inmigración (y ahora también de asilo) porque la idea de la "Europa fortaleza" se resquebrajaba ante la llegada cada vez más numerosa de emigrantes. Como era un problema que afectaba casi en exclusiva a los países de entrada en Europa, los países del sur (Grecia, Italia y también España), la UE no se había preocupado de establecer esa política común europea. Ahora, han tenido que adoptar medidas, de una forma precipitada, polémica y que no garantiza en absoluto el buen resultado ni es garantista con respecto al estatuto del refugiado. La decisión histórica, adoptada por Reino Unido, tras aprobar mediante referéndum celebrado el 23 de junio de 2016 -cuando acabamos de escribir estas páginassu salida de la Unión Europea, hace que se tome conciencia de que la Unión Europea no es un proceso irreversible. El tema de la inmigración, que ha influido en gran medida en la decisión de los británicos de limitar la circulación de personas y retomar las riendas de sus fronteras, pone de manifiesto el recelo que hay con respecto a los flujos de inmigrantes procedentes de la propia UE y, sobre todo, de los extracomunitarios. Aún es pronto para hacer valoraciones pero no auguramos que la política común errante de la UE sobre asilo que se ha adoptado pueda resolver la situación tan compleja como la que actualmente se presenta para la ahora, ya Unión Europea de 27 miembros.

\section{BIBLIOGRAFÍA}

AÑÓN ROIG, Maj., "Integración: una cuestión de derechos", Revista Arbor, n. 477, 2010, pp.625638.

BELLOSO MARTín, Nuria. Os novos desafíos da cidadanía. Coleçâo Direito e Sociedade Contemporánea. Trad. al portugués de C. Gorczevski. Servicio de Publicaciones de la Universidade de Santa Cruz do Sul -EDUNISC- (Brasil), 2005.

BONDIA, D., "El sistema europeu de protecció dels drets humans", en J. BONET y V. M. SÁNCHEZ (dirs), Els drets humans al segle XXI: continuïtat i canvis, Barcelona, Huygens Editorial, 2007, pp. 207-241.

DE LUCAS, J., "Fundamentos filosóficos del derecho de asilo" en Derechos y Libertades, Universidad Carlos III de Madrid. Instituto Bartolomé de las Casas- BOE, enero-junio 1995, pp.23-56. http://e-archivo.uc3m.es/handle/10016/1234\#preview.

DE LUCAS, J., Puertas que se cierran. Europa como fortaleza, Barcelona, Icaria, 1996.

DE LUCAS, J., "Dos test sobre la consistencia del Estado de Derecho. Ante los proyectos de reforma de asilo y extranjería", Jueces para la democracia, no 64, 2009, pp. 15-23 y "Sobre los fundamentos de la igualdad y del reconocimiento. Un análisis crítico de las condiciones de las políticas europeas de integración ante la inmigración", en AA. VV., Inmigración e integración en la UE. Dos retos para el siglo XXI, Bilbao, Eurobask, 2012, pp. 11-91.

DíEZ DE VELASCO, M., Instituciones de Derecho Internacional público, T.I, 12ªed., Madrid, Tecnos, 1999. 
GONZÁLEZ AMUCHASTEGUI, J: «Notas para la elaboración de un concepto de solidaridad como principio político», en Sistema. Revista de Ciencias Sociales, n 101, Marzo 1991, págs. 123 y ss

GORCZEVSKI, C; BELLOSO MARTÍN, N., A necessária revisao do conceito de cidadania: movimentos sociais e novos protagonistas na esfera pública democrática. Porto Alegre: EDUNISC, 2011. Disponible en: <http://www.unisc.br/portal/pt/editora/e-books.html>.

FERNÁNDEZ SEGADO, F., "la solidaridad como principio constitucional" en UNED. Teoría y Realidad Constitucional, núm. $30, \quad 2012, \quad$ pp. 139-181. Disponible en: <dialnet.unirioja.es/descarga/articulo/4097796.pdf> (Consultado el 14.08.2015).

FIBLA, C., "Huyen del horror y acaban en el infierno" en El Notario del siglo XXI, Revista del Colegio Notarial de Madrid, n67,mayo-junio 2016, pp.34-37.

GARCíA AÑÓN, J., "Discriminación, exclusión social y conflicto en sociedades multiculturales: la identificación por perfil étnico", en J. GARCÍA AÑÓN y M. RUIZ SANZ (eds.), Discriminación racial y étnica, Valencia, Tirant lo Blanch, 2012, pp. 281-316.

HABERMAS, J., "La idea de dignidad humana y la utopía realista de los derechos humanos", Análes de la Cátedra Francisco Suárez, nº 44, 2010, pp. 105-121.

JIMÉNEZ REDONDO, J.C., El valor de la solidaridad en un mundo global, CEU Ediciones, Madrid, 2010, pp. 11-12.

LLUNCH, T., "Hacia una política común de asilo para la Unión Europe Afers Internacionals, núm. 53, Fundació CIDOB, 2001, pp. 141-146. Disponible en: < http://www.raco.cat/index.php/revistacidob/article/viewFile/28222/28056>. (Acceso el 14.06.2016).

LOSANO, M.G., "Las teorías del solidarismo y su influencia en la formulación de los derechos fundamentales económicos" en Losano, M.G. (Editor) Solidaridad y derechos humanos en tiempos de crisis, Madrid, Dykinson-Instituto de Derechos Humanos Bartolomé de las Casas, Universidad Carlos III de Madrid, 2013.

MARIÑO MENÉNDEZ, F., "Los derechos de los extranjeros en el Derecho Internacional" en Capítulo IV de Derecho de extranjería, asilo y refugio, F. Mariño Menéndez y otros, Madrid, Ministerio de Asuntos Sociales, 1996, pp.505-526.

MARTíN ARRIBAS, J.J., Los Estados Europeos frente al desafío de los refugiados y el derecho de asilo, Madrid, Dykinson-Universidad de Burgos, 2000.

MARTÍNEZ DE PISÓN, J., "Ciudadanía e inmigración". En: Ciudadanía. Dinámicas de pertenencia y exclusión. (Coordinadores: Ma.J. Bernuz Beneítez y R. Susín Betrán). Servicio de Publicaciones de la Universidad de La Rioja, 2003.

RUIZ VIEYTEZ, E.J., Juntos pero no revueltos. Sobre diversidad cultural, democracia y derechos humanos, Madrid, Maia, 2011, pp. 198-208.

SÁNCHEZ LEGIDO, A., "Entre la obsesión por la seguridad y la lucha contra la inmigración irregular: a propósito de la nueva Ley de asilo", Revista Electrónica de Estudios Internacionales, nº 18, 2009.

SOLANES, A., "Asilo: un derecho en cuestión. Análisis desde la realidad española a la luz de las disposiciones europeas" en Revista Acadêmica, vol.85, n², 2013, pp.50-97. Disponible en: < www.repositorios.ufpe.br/revistas/index.php/ACADEMICA/article/download/.../426>. (Acceso el 05.06.2016).

SOLANES CORELLA, Ma A., "Derechos humanos y asilo: sobre las deficiencias del SECA y la regulación jurídica española" en Anuario de la Facultad de Derecho - Universidad de Alcalá VII (2014) 181-210.

SOLANES CORELLA, Ma A. (Editora), Diversidad cultural y conflictos en la Unión Europea. Implicaciones jurídico-políticas, Valencia, Tirant lo Blanch, 2016.

VANELLA, Vilma, "Convenios de convivencia asistencial. Necesidad de su regulación legal contemplando todo tipo de convivencias", LA LEY, 2011. 


\section{ACUERDOS, DIRECTIVAS, INFORMES}

Acuerdo UE-Turquía frente a las garantías en materia de asilo. Disponible en: $<$ http://iniciativadebate.org/2016/04/01/acuerdo-ue-turquia-casi-trafico-personas/> (Acceso el 0404.2016).

http://www.consilium.europa.eu/es/press/press-releases/2016/03/07-eu-turkey-meeting-statement/. ACNUR, Directrices de protección internacional: Solicitudes de asilo de niños bajo los artículos 1(A)2 y 1(F) de la Convención de 1951 y/o protocolo de 1967 sobre el Estatuto de los Refugiados, 2009 y Menores no acompañados y la protección de asilo. 2009. Disponible en: < http://www.unhcr.org/5730cad27.pdf>. (Acceso el 05.06.2016).

ACNUR sobre el acuerdo UE-Turquía: deben prevalecer las garantías en materia de asilo. Disponible en: http://www.acnur.org/t3/noticias/noticia/posicion-de-acnur-sobre-el-acuerdo-ue-turquia-debenprevalecer-las-garantias-en-materia-de-asilo/.

ACNUR, Plan de los 10 puntos. Disponible en: <http://docplayer.es/11549483-La-proteccion-de-losrefugiados-y-la-migracion-mixta-el-plan-de-los-10-puntos-en-accion-comision-europea-ayudahumanitaria.html>. (Acceso el 15.04.2016).

ACNUR, Directrices de protección internacional: Solicitudes de asilo de niños bajo los artículos 1(A)2 y 1(F) de la Convención de 1951 y/o protocolo de 1967 sobre el Estatuto de los Refugiados, 2009 y Menores no acompañados y la protección de asilo. 2009. Disponible en: < http://www.unhcr.org/5730cad27.pdf>. (Acceso el 05.06.2016).

Agencia Europea de Fronteras (FRONTEX) alertaba sobre la existencia de un tráfico de pasaportes sirios falsos para facilitar la entrada de inmigrantes en la Unión Europea. Disponible en: < http://www.abc.es/internacional/20150901/abci-pasaportes-falsos-siria-201509011111.html>. (Acceso el 09.06.2016).

Carta de los Derechos Fundamentales de la Unión Europea, año 2000. Disponible en: $<$ ttp://www.europarl.europa.eu/charter/pdf/text_es.pdf>.

Comité DESC informa sobre España, <http://eur-lex.europa.eu/legalcontent/ES/TXT/?uri=CELEX\%3A62006CJ0133>.

Directiva 2004/83/CE, del Consejo, de 29 de abril, por la que se establecen normas mínimas relativas a los requisitos para el reconocimiento y el estatuto de nacionales de terceros países o apátridas como refugiados o personas que necesitan otro tipo de protección internacional y al contenido de la protección concedida. Disponible en: $<$ http://eur-lex.europa.eu/legalcontent/ES/TXT/?uri=URISERV\%3Al33176>. (Acceso el 03.03.2016).

Directiva 2005/85/CE, del Consejo, de 1 de diciembre, sobre normas mínimas para los procedimientos que deben aplicar los Estados miembros para conceder o retirar la condición de refugiado. Disponible en: <https://www.boe.es/doue/2005/326/L00013-00034.pdf > (Acceso el 04.03.2016).

Directiva 2003/86/CE, del Consejo, de 22 de septiembre, sobre el derecho de reagrupación familiar relativo a los refugiados. Disponible en: <eur-lex.europa.eu > EUROPA > EU law and publications > EUR-Lex >. (Acceso el 02.03.2016). 
EASO http://eur-lex.europa.eu/legal-content/ES/TXT/?uri=URISERV\%3Ajl0022

EDWARDS, A., “¿'Refugiado' o 'Migrante’? ACNUR insta a usar el término correcto”. Disponible en: http://www.acnur.org/t3/noticias/noticia/refugiado-o-migrante-acnur-insta-a-usar-el-termino-correcto/.

Sistema Eurodac. Disponible en: <http://eur-lex.europa.eu/legalcontent/ES/TXT/?uri=URISERV\%3Al33081>. (Acceso el 17.06.2016).

Manual y Directrices sobre procedimientos y criterios para determinar la condición de refugiado, en virtud de la Convención de 1951 y el Protocolo de 1967 sobre el estatuto de los refugiados. Reedición. Ginebra, diciembre de 2011, UNHCR-ACNUR, pp.7-8. Disponible en: $<$ http://www.refworld.org/cgi-bin/texis/vtx/rwmain/opendocpdf.pdf?reldoc=y\&docid=50c1a04a2>.

(Acceso el 11.06.2016).

Ley $12 / 2009$, de 30 de octubre, reguladora del derecho de asilo y de la protección subsidiaria. Disponible en: <https://www.boe.es/buscar/act.php?id=BOE-A-2009-17242>.

"Un sistema común europeo de asilo". http://ec.europa.eu/dgs/home-affairs/e-library/docs/ceas-factsheets/ceas_factsheet_es.pdf. (Acceso el 10.06.2016).

Manual de Derecho Europeo sobre asilo, fronteras inmigración. Agencia de los Derechos Fundamentales de la Unión Europea, 2014. Disponible en: < http://fra.europa.eu/sites/default/files/handbook-law-asylum-migration-borders-2nded_es.pdf> .

(Acceso el 15.06.2016).

Oficina Europea de Apoyo al Asilo (EASO). Disponible en: http://eur-lex.europa.eu/legalcontent/ES/TXT/?uri=URISERV\%3Ajl0022. (Acceso el 14.06.2016).

Parlamento Europeo, Resolución del Parlamento Europeo, de 13 de diciembre de 2012, sobre la revisión de la estrategia de la Unión Europea en materia de derechos humanos. Disponible en: $<$ http://www.consilium.europa.eu/es/press/press-releases/2015/07/20-fac-human-rights/>.

"La Política de Asilo en la UE". Disponible en: http://www.europarl.europa.eu/ftu/pdf/es/FTU_5.12.2.pdf. (Acceso el 14.06.2016).

POSICIÓN COMÚN de 4 de marzo de 1996 definida por el Consejo, sobre la base del artículo K.3 del Tratado de la Unión Europea relativa a la aplicación armonizada de la definición del término «refugiado» conforme al artículo 1 de la Convención de Ginebra de 28 de julio de 1951 sobre el Estatuto de los Refugiados (96/196/JAl). Disponible en: http://www.acnur.org/t3/fileadmin/Documentos/BDL/2008/6033.pdf?view=1. (Acceso el 11.06.2016).

Resolución del Consejo de 20 de junio de 1995 sobre las garantías mínimas para los procedimientos de asilo [Diario Oficial C 274 de 19.09.1996]. Disponible en: http://eur-lex.europa.eu/legalcontent/ES/TXT/?uri=URISERV\%3AI33103. (Acceso el 11.06.2016).

REGLAMENTO (UE) No 604/2013 DEL PARLAMENTO EUROPEO Y DEL CONSEJO de 26 de junio de 2013 por el que se establecen los criterios y mecanismos de determinación del Estado miembro responsable del examen de una solicitud de protección internacional presentada en uno de los Estados miembros por un nacional de un tercer país o un apátrida (Texto refundido). Disponible en: < https://www.boe.es/doue/2013/180/L00031-00059.pdf>. (Acceso el 11.06.2016).

Sistema de Información Schengen (SIS). Disponible en: <http://eur-lex.europa.eu/legalcontent/ES/TXT/?uri=URISERV\%3AI33020>. 
¿La globalización de la indiferencia?

Algunas reflexiones sobre los desplazados, los migrantes y los refugiados en la Unión Europea

Tratado de la Unión Europea. Versión consolidada. Disponible en: < http://www.boe.es/doue/2010/083/Z00013-00046.pdf>. (Acceso el 15.06.2016).

Tratado de Funcionamiento de la Unión Europea. Disponible en: < http://europa.eu/pol/pdf/consolidated-treaties_es.pdf\#page=57>.

TRATADO DE LISBOA POR EL QUE SE MODIFICAN EL TRATADO DE LA UNIÓN EUROPEA Y EL TRATADO CONSTITUTIVO DE LA COMUNIDAD EUROPEA (2007/C 306/01). Disponible en: < https://www.boe.es/legislacion/enlaces/documentos/ue/Trat_lisboa.pdf>.

\section{JURISPRUDENCIA}

Sentencia del Tribunal de Justicia (Gran sala) de 6 de mayo de 2008, Asunto C 133/06, Parlamento Europeo contra Consejo de la Unión Europea, que dispone: "Anular los artículos 29, apartados 1 y 2 , y 36, apartado 3, de la Directiva 2005/85/CE del Consejo, de 1 de diciembre de 2005, sobre normas mínimas para los procedimientos que deben aplicar los Estados miembros para conceder o retirar la condición de refugiado" Disponible en: <.http://eur-lex.europa.eu/legalcontent/ES/TXT/?uri=CELEX\%3A62006CJ0133>. (Acceso el 07.06.2016).

\section{DIARIOS}

Diario ABC (02.09.2014). Disponible en: <http://www.abc.es/espana/20150902/abci-diferenciasmigrante-refugiado-201509011803.html>.

Diario "El Periódico". Disponible en: <http://www.elperiodico.com/es/noticias/internacional/imagenaylan-nino-sin-vida-una-playa-turca-vuelve-inmediato-simbolo-4476423>. (Acceso el 05.06.2016).

Diario El País, 06.01.2016. Disponible http://internacional.elpais.com/internacional/2016/01/05/actualidad/1451991976_936738.html.

(Acceso el 10.06.2016).

"Referédum sobre el Brexit". Diario El País, 24.06.2016. Disponible en. http://internacional.elpais.com/internacional/2016/06/15/actualidad/1465985703_933248.html.

(Acceso el 24.06.2016).

"Referéndum de permanencia en la UE Reino Unido vota por dejar la Unión Europea". Diario El País, 24.06.2016.

Disponible

en:

http://internacional.elpais.com/internacional/2016/06/24/actualidad/1466741749_403437.html?rel=cx_ articulo\#cxrecs_s. (Acceso el 24.06.2016).

\section{COMO CITAR ESSE DOCUMENTO:}

MARTín, Núria Belloso. ¿La globalización de la indiferencia? algunas reflexiones sobre los desplazados, los migrantes y los refugiados en la Unión Europea. Revista do Direito, Santa Cruz do Sul, v. 3, n. 50, p. 139-174, set. 2016. ISSN 1982-9957. Disponível em: <https://online.unisc.br/seer/index.php/direito/article/view/8406>. Acesso em: doi:http://dx.doi.org/10.17058/rdunisc.v3i50.8406. 